\title{
Immune Mediated Diseases and Immune Modulation in the Neurocritical Care Unit
}

\author{
Gloria von Geldern • Thomas McPharlin • Kyra Becker
}

Published online: 13 December 2011

(C) The American Society for Experimental NeuroTherapeutics, Inc. 2011

\begin{abstract}
This chapter will review the spectrum of immunemediated diseases that affect the nervous system and may result in an admission to the neurological intensive care unit. Immunomodulatory strategies to treat acute exacerbations of neurological diseases caused by aberrant immune responses are discussed, but strategies for long-term immunosuppression are not presented. The recommendations for therapeutic intervention are based on a synthesis of the literature, and include recommendations by the Cochrane Collaborative, the American Academy of Neurology, and other key organizations. References from recent publications are provided for the disorders and therapies in which randomized clinical trials and large evidenced-based reviews do not exist. The chapter concludes with a brief review of the mechanisms of action, dosing, and side effects of commonly used immunosuppressive strategies in the neurocritical care unit.
\end{abstract}

Keywords Immunomodulation - Autoimmune ·

Plasmapheresis · Corticosteroids · Intravenous immunoglobulin $\cdot$ Cyclophosphamide $\cdot$ Rituximab

G. von Geldern

Department of Neurology, Johns Hopkins School of Medicine,

Baltimore, MD 21287, USA

T. McPharlin

University of Washington School of Pharmacy,

Seattle, WA 98104, USA

K. Becker $(\square)$

Department of Neurology,

University of Washington School of Medicine,

Seattle, WA 98104, USA

e-mail: kjb@uw.edu

\section{Immune-mediated Diseases That Affect the Nervous System}

Demyelinating Diseases

\section{Multiple Sclerosis}

Multiple sclerosis (MS) is the most common immunemediated disease of the central nervous system (CNS) and the leading cause of nontraumatic disability among young adults in Western countries [1]. The course may be relapsing and remitting or chronic and progressive. The incidence of MS in Europe and North America is between 50 and 70 per million of the population [1]. Patients with MS have a threefold increase in mortality and a shorter life expectancy than the general population (by 6-12 years), and half of the deaths that occur are related to MS itself [2-6].

Autoimmune responses to myelin-associated peptides, including myelin basic protein, proteolipid protein, and myelin oligodendrocytes glycoprotein are seen in patients with MS $[7,8]$. The immune responses to these antigens may be either cellular or humoral, and the described pathology is quite varied [9]. The effect of immune-modulating treatments on disease activity would thus be expected to vary depending on the predominant pathophysiology, although in general practice the underlying immunopathology for a given individual is not known.

A full discussion of MS, its diagnosis, and the approaches to chronic immunosuppression are beyond the scope of this chapter; therefore, readers are referred to several recent reviews for additional information [10-12]. Comments regarding the treatment of MS will be restricted to those atypical presentations that may necessitate intensive care unit (ICU) admission, which primarily occurs with the rare tumefactive 
variants of MS and include Schilder's disease, Marburg disease, and Balo's concentric sclerosis. Magnetic resonance imaging (MRI) generally shows a single large demyelinating lesion associated with marked edema and mass effect [13]. Symptoms include focal neurological deficits and seizures. For patients with larger lesions, decreased level of consciousness can occur due to elevated intracranial pressure and incipient herniation. MRI, including magnetic resonance spectroscopy, can be helpful in distinguishing tumefactive lesions from true tumors, but biopsy may be necessary for definitive diagnosis [14-16]. Tumefactive lesions can also be mistaken for severe acute disseminated encephalomyelitis (ADEM), and ADEM should be considered in the differential, especially in patients with fever, recent illness, or recent vaccine. Tumefactive lesions are also reported in patients with neuromyelitis optica (NMO) spectrum disorders [17-20].

High-dose parenteral corticosteroids are the primary therapy for the treatment of acute MS exacerbations, including tumefactive MS [21, 22]. Based on a single randomized clinical trial (RCT), plasmapheresis may also have some benefit for treating exacerbations in patients with relapsing-remitting disease [23]. Intravenous immune globulin (IVIG) does not appear have any benefit as an adjunct therapy to methylprednisolone in the treatment of MS exacerbations, and generally it is also not recommended [24]. Because the mass effect associated with tumefactive lesions can potentially lead to herniation, osmotic therapy is often instituted concomitant with corticosteroids, and decompressive hemicraniectomy has been reported in the treatment of tumefactive MS [25].

\section{Neuromyelitis Optica}

NMO is an inflammatory demyelinating disorder of the CNS that primarily affects the optic nerves (optic neuritis) and the spinal cord (myelitis). NMO is rare and accounts for only $1 \%$ of all demyelinating diseases [26-28]. The incidence of NMO is estimated to be approximately 4 per million of the population and the prevalence is somewhere between 3 and 44 per million, depending on ethnicity and geographic location [26-29]. Disease onset is usually in the fourth decade of life; women are affected more commonly than men (approximately 3:1); and non-Caucasians (especially Japanese) are affected more commonly than Caucasians [29-32]. Most patients with NMO (60-90\%) have autoantibodies directed toward the aquaporin 4 (AQP4) channel, and these antibodies are thought to be pathogenic $[29,33]$. AQP4 is the most common water channel in the brain and is expressed on astrocytes of the glia limitans. NMO immunoglobulin (Ig) G antibodies can induce breakdown of the blood-brain barrier and cause destruction of the astrocytes that express AQP4 [34-36].

Patients with NMO can present with a monophasic illness, but more commonly have a relapsing-remitting course.
The visual loss in NMO tends to be more severe than in MS and can affect both eyes simultaneously or in rapid succession [30, 37, 38]. Spinal cord involvement is longitudinally extensive ( $\geq 3$ vertebral segments) in patients with NMO in contrast to the spinal lesions seen in patients with MS, which are much more limited in extent [39]. Respiratory function can be affected by spinal lesions that extend into the brainstem, but isolated brainstem lesions leading to respiratory compromise have also been described $[29,40]$. The prognosis appears to be particularly poor in patients who require mechanical ventilatory support [40]. The 5-year mortality in NMO is reported to be as high as $32 \%$, with most deaths occurring due to respiratory failure [41, 42]. Because NMO can present with tumefactive lesions, brain death due to herniation has also been described [20].

The diagnosis of NMO requires the appropriate constellation of clinical symptoms (optic neuritis and transverse myelitis) plus 2 of the following: MRI imaging demonstrating extensive longitudinal involvement of the spinal cord; MRI imaging of the brain not meeting diagnostic criteria for MS; identification of AQP4 antibodies in the serum or cerebrospinal fluid (CSF) [43]. The AQP4 antibodies are fairly specific for NMO but have limited sensitivity, and thus seronegative patients can be diagnosed with NMO [44]. CSF analysis may show pleocytosis and elevated protein, and oligoclonal bands (OCBs) may be seen, but are much less common than in MS [29, 38, 45].

There are no RCTs addressing the best approach to immunodulation in patients with NMO. The standard approach for treating acute attacks is similar to that for the treatment of MS exacerbations and consists of high-dose parenteral corticosteroids followed by a gradual oral corticosteroid taper [45]. Most literature suggests that plasmapheresis is of benefit, and plasmapheresis is generally recommended when corticosteroids are not effective [23, 45-47]. The utility of IVIG in the treatment of acute NMO has not been adequately studied. A variety of immunosuppressive drugs, including rituximab, mitoxantrone, mycophenolate mofetil (MMF), and azathioprine have been used to prevent relapses of NMO, but their effectiveness in the treatment of acute exacerbations is unknown [48-52].

\section{$A D E M$}

ADEM is a monophasic disorder characterized by acute inflammation of the brain and spinal cord. ADEM is most common in children, with an incidence of approximately 4 per million of the population who are $<20$ years of age (and even higher among younger children) [53]. Adults can develop ADEM, but it is uncommon. Symptom onset usually occurs within days to weeks after a trivial infection or a vaccination, but ADEM can also occur without a clear precipitant $[54,55]$. Pathogens associated with ADEM include a 
number of different viruses, $\beta$-hemolytic streptococci, and intracellular bacteria, such as Mycoplasma pneumonia [56]. Symptoms vary, but may include diffuse encephalopathy, focal neurological signs, and seizures [55]. Maximal neurological deficits usually occur within hours to a few days after symptom onset. There are no specific diagnostic criteria for ADEM, and the diagnosis generally relies on the exclusion of other disorders (such as MS). MRI shows multifocal T2 and fluid attenuation inversion recovery (FLAIR) FLAIR-weighted lesions, which may faintly enhance, and the spinal cord is involved in most cases $[55,57]$. The lesions can show restricted diffusion in the acute phase [58]. CSF analysis shows elevated protein and/or pleocytosis in most patients [54]. In distinction from MS, OCBs are rare in ADEM [59]. Acute hemorrhagic leukoencephalitis (AHLE), or Hurst's Disease, is considered to be a more severe type of ADEM by some and a distinct clinical entity by others. The clinical characteristics of AHLE are quite similar to those for ADEM, but AHLE may preferentially affect the brainstem, and as the name suggests, the lesions are hemorrhagic. Red blood cells, as well as polymorphonuclear cells, are generally present in the CSF of patients with AHLE, whereas OCBs are rare [60-62].

The pathophysiology of ADEM and AHLE is thought to be related to either molecular mimicry, with the immune response to the pathogen cross reacting to components of myelin, or to direct pathogen-mediated injury of the brain, with altered antigens exposed to the immune system precipitating an immune response. A high proportion of patients with ADEM, especially children, are found to have antibodies directed toward myelin oligodendrocytes glycoprotein [63-66]. AHLE has been reported to occur in the context of several different viral infections, including cytomegalovirus, Epstein Barr virus, herpes simplex virus, the mumps virus, and the H1N1 virus [67-71].

There are no RCTs addressing appropriate therapy for ADEM; recommendations regarding therapeutic interventions are therefore limited and based on anecdotes and case series. Prior to institution of immune modulating therapy, the possibility of infectious encephalitis should be excluded. Treatment with high-dose parental corticosteroids (followed by an oral taper) is considered to be the standard of care. Plasmapheresis and/or IVIG may be of benefit for patients who fail to respond to corticosteroids [23]. Finally, in both ADEM and AHLE, the brain lesions can be associated with significant edema. The mass effect associated with these lesions can be life-threatening, and measures to reduce brain swelling, including hypothermia and craniectomy, may be needed [72-75]. In addition to demyelination, pathology in AHLE shows fibrinoid necrosis of small vessels [62]. Outcome is poor in patients who have AHLE, with mortality approaching 70\% [62]. Patients with ADEM have a much better outcome, but approximately one third of them will go on to develop MS [76].

\section{Acute Transverse Myelitis}

Acute transverse myelitis (ATM) describes the involvement of the spinal cord by any inflammatory process that leads to sensory, motor, or autonomic dysfunction. Demyelinating disorders, such as MS and NMO, are probably the most common causes of ATM. Absent MS and NMO, most cases of ATM appear to follow an infection or vaccination, although the etiology of ATM is not determined in up to $30 \%$ of cases [77]. Rarely, systemic autoimmune disorders, such as systemic lupus erythematosis (SLE) and Sjögren's Syndrome can affect the spinal cord [77]. The reported incidence of ATM depends on whether or not patients with MS and NMO are included in the estimate. Overall, there are approximately 25 cases of ATM per million of the population each year; if patients with MS and NMO are excluded, the annual incidence of ATM is somewhere between 1 and 8 per million, with a peak incidence between the ages of 10 and 19 and 30 and 39 [77-79].

The onset of symptoms in ATM can be either acute or subacute, and symptoms usually peak within 4 hours to 21 days of onset (median time to maximum deficit is 3 days) [80]. Clinical examination generally reveals a clear sensory level. The cord involvement, by definition, is bilateral, but not necessarily symmetric. The diagnostic criteria suggest that there be evidence of spinal cord inflammation, either by MRI imaging (gadolinium enhancement of the cord) or by CSF analysis (pleocytosis and/or an elevated IgG index), but in reality, many patients with ATM have neither $[78,79]$. The differential diagnosis of longitudinally extensive cord lesions ( $\geq 3$ vertebral levels) also includes NMO, SLE, sarcoidosis, Sjögren's Syndrome, and spinal ischemia [81-83]. Extrinsic compression of the cord, neoplastic and vascular etiologies, and radiation-induced changes of the cord must be excluded before the diagnosis of ATM can be made. MS should also be considered in the differential of ATM, although the cord involvement in MS is generally more discrete and spans $<2$ vertebral levels [80]. Furthermore, MRI of the brain should be normal in patients with ATM, whereas patients with MS will often have evidence demyelination [78].

There are no RCTs to define the optimal treatment for ATM, but high-dose parenteral corticosteroids are the standard of care [84]. Limited data suggest that plasmapheresis may be of benefit for patients with ATM that fail to respond to high-dose treatment with corticosteroids [23, 85, 86]. Outcome from ATM can be predicted by the severity of symptoms at presentation. Patients with a very rapid onset of symptoms and features of spinal shock are especially prone to poor outcome $[78,80]$.

\section{Guillain-Barré Syndrome}

Acute inflammatory demyelinating polyneuropathy (AIDP) or Guillain-Barré syndrome (GBS) is perhaps the prototypical 
immunologically mediated neurological illness prompting admission to the ICU. The incidence of AIDP/GBS is roughly 12 to 19 per million of the population per year, and males are more commonly affected than females [87]. The diagnosis of AIDP/GBS depends on the appropriate clinical presentation with ascending weakness and the finding of areflexia. By definition, patients should present within 4 weeks of symptom onset, although the mean time from symptom onset to maximal symptoms is approximately 10 days [88]. CSF analysis usually reveals elevated protein and few cells (cytoalbuminemic dissociation). Electrical studies show absent $\mathrm{F}$ waves. The differential diagnosis for acute onset of flaccid paralysis is fairly extensive, but it is important to note the recent addition of west Nile virus to the differential [89].

Patients with AIDP/GBS often require mechanical ventilation and AIDP/GBS is one of the most common causes of neuromuscular respiratory failure [90]. Autonomic instability is also very common, with dramatic fluctuations in blood pressure and heart rate. Symptomatic bradycardia has also led to the need for pacemaker implantation in some patients [91-96].

The clinical trials in AIDP/GBS have largely been performed in patients with moderate-to-severe disease (unable to walk) early after symptom onset (within 2 weeks). Plasmapheresis is the only therapy shown to be superior to supportive care alone [97]. Administration of IVIG is as effective as plasmapheresis, but the combination of plasmapheresis and IVIG offers no benefit over plasmapheresis alone [98]. Importantly, corticosteroids are ineffective in the treatment of GBS [99]. The usefulness of plasmapheresis and IVIG in patients with milder symptoms at presentation and in those who have had more than 2 weeks of symptoms is unknown. That plasmapheresis may be of benefit in patients without severe disease, however, was suggested by a large multicenter study that found 2 sessions of plasmapheresis to be better than none in mildly affected patients and that 4 sessions of plasmapheresis were better than 2 in moderately affected patients, indicating a dose response [100].

Current recommendations are that plasmapheresis should be offered to patients with AIDP/GBS who are unable to walk independently or who require mechanical ventilation. For patients with milder presentations of AIDP/GBS, plasmapheresis should also be considered, but the data to support this recommendation are not as robust. IVIG is a reasonable alternative to plasmapheresis, and the data do not support the superiority of one treatment over another $[23,98]$. Despite improvement in ICU care and advances in immunotherapy, the mortality in patients with AIDP/GBS are still at least 2 to $3 \%$, and may even approach $10 \%$ [88, 101-103]. Advanced age and the presence of medical comorbidities are the most potent predictors of poor outcome [104-106].

\section{Miller-Fisher Syndrome}

Miller-Fisher Syndrome (MFS) is a variant of GBS and is characterized by impaired eye movements (ophthalmaplegia), incoordination (ataxia), and loss of tendon reflexes (areflexia). Bickerstaff's Brainstem Encephalitis (BBE) is similar to MFS, but patients with BBE have upper motor neuron signs and impaired consciousness. Diplopia and gait impairment are the most common presenting symptoms for both disorders, and these symptoms often develop on the same day [107]. The annual incidence for MFS is approximately 1 per million of the population; BBE is much less common. Men appear to be affected more commonly then women, especially with BBE [107].

MFS and BBE are considered to be a single autoimmune disease with variable involvement of the CNS and peripheral nervous system (PNS). The suggestion that MFS and $\mathrm{BBE}$ have a common pathogenesis is based on the fact that anti-GQ1b IgG antibodies and antecedent Campylobacter jejuni or Haemophilus influenza infections may be seen in both disorders [107-109]. The classic CSF finding of cytoalbuminemic dissociation is a bit more common in MFS, whereas pleocytosis is a bit more common in BBE, but these differences do not discriminate between the 2 disorders [107]. And given that impaired consciousness is necessary to diagnose BBE, it is not surprising that patients with BBE are more likely to have MRI evidence of brainstem involvement than patients with MFS $[107,110]$. The neurophysiological findings (absent soleus H-reflex) are also common in both conditions [107].

There are no RCTs assessing therapeutic options in either MFS or BBE, but case series describe successful use of plasmapheresis and high-dose parenteral corticosteroids [111]. The usefulness of IVIG is unclear [112].

\section{Primary CNS Vasculitides}

\section{Primary Angiitis of the Central Nervous System}

Primary angiitis of the central nervous system (PACNS) is a rare disorder associated with significant morbidity and mortality. The annual incidence is approximately 2 per million of the population, and it occurs more commonly in men, with the onset usually in the fifth decade of life $[113,114]$. Patients generally present with headache and encephalopathy; strokes may also occur. MRI is almost always abnormal, but the imaging findings are nonspecific. CSF may show evidence of mild inflammation, with pleocytosis, and an elevated protein level, but the CSF may also be normal. Systemic markers of inflammation, such as plasma high sensitivity C-reactive protein and the erythrocyte sedimentation rate are generally normal. Angiography may reveal typical findings of beading, with arterial narrowing followed 
by arterial dilation. The differential diagnosis of PACNS includes the reversible cerebral vasoconstriction syndrome, which is a self-limited disorder that occurs in individuals following exposure to vasoactive substances $[115,116]$.

Brain biopsy is the gold standard for diagnosis of PACNS, but false negative biopsies do occur [117]. Biopsy yield may be better if it is directed to an area of enhancement on MRI [118]. PACNS affects both medium and small arteries of the meninges and cortex. Typical histological findings include lymphocytic cellular infiltrates with a variable number of plasma cells, histiocytes, neutrophils, and eosinophils. In some cases, the inflammatory infiltrate may be granulomatous or necrotizing [118]. Patients with granulomatous angiitis of the CNS tend to do more poorly than those with PACNS and often require more aggressive immunosuppressive therapy [119].

There are no RCTs to address appropriate therapy for PACNS. Treatment is generally initiated with high-dose corticosteroids and is often followed by cyclophosphamide [119]. Relapse is common and occurs in up to $25 \%$ of patients [113]. Successful therapy with tumor necrosis factor (TNF)- $\alpha$ inhibitors, rituximab, and MMF has been described [120-122]. Recent reports suggest that mortality and severe morbidity is seen in at least $14 \%$ of patients 1 year after diagnosis [118].

\section{Cerebral Amyloid Angiopathy-Related Inflammation}

Some patients with cerebral amyloid angiopathy (CAA) develop a marked CNS inflammatory response resulting in cerebral edema and mass effect. These individuals present with the acute or subacute onset of headaches, cognitive and behavioral changes, seizures, and focal neurological deficits. CAA with inflammation is rare and is thought to be due to an inflammatory response to $\beta$ amyloid $(A \beta)$ in the walls of blood vessels [123, 124]. This hypothesis is supported by the observation that a subset of patients with Alzheimer's disease undergoing experimental therapy with an antibody directed toward $A \beta$ developed a syndrome closely resembling spontaneous CAA-related inflammation [125]. Further, recent reports indicate that patients with CCA-related inflammation have antibodies directed toward $A \beta$, suggesting that an aberrant immunological response is responsible for the inflammation $[126,127]$.

Patients with CAA-related inflammation tend to be younger (seventh decade of life) than patients with CAA and no inflammation (eighth decade of life) and are more likely to be men [128]. In cases in which genotyping has been performed, most patients have the apoe $\varepsilon 4 / \varepsilon 4$ genotype [129]. CSF analysis may show elevated protein and/or pleocytosis [129]. An MRI typically shows asymmetric white matter hyperintensities on T2 or FLAIR-weighted sequences, and in some cases, resembles a tumor [128]. Patchy contrast enhancement may be seen in both the leptomeninges and in the parenchymal lesions [130]. Susceptibility weighted imaging sequences show evidence of prior hemorrhage (usually microhemorrhages) [129]. Cerebral angiography is generally normal, despite the fact that the pathology is due to vascular inflammation [129].

Definitive diagnosis of CAA-related inflammation requires biopsy, although empiric immunomodulatory therapy can be used once the possibility of infection has been eliminated. First line therapy is usually parenteral corticosteroids, and the response to corticosteroids is generally good [128, 129, 131, 132]. In some cases, additional immunosuppressive agents, primarily cyclophosphamide, have been used [128]. Most patients have a monophasic illness without recurrent symptoms [128].

\section{Giant Cell Arteritis}

Giant cell arteritis (GCA) should be included in the differential of CNS vasculitis. This disorder typically affects the medium and large extracranial vessels. Involvement of the central retinal, posterior ciliary, and ophthalmic arteries can lead to visual loss. Patients with GCA are generally older ( $>50$ years of age), women are affected more commonly then men, and Caucasians are affected more commonly than non-Caucasians. The incidence in Europe and North America is 200 to 300 per million of this population [133]. Typical presenting symptoms include visual disturbance, jaw claudication, and tenderness of the superficial temporal arteries (STAs). The erythrocyte sedimentation rate is generally elevated $(>50 \mathrm{~mm} / \mathrm{h})$, as is the high sensitivity Creactive protein, but both can also be normal. Examination should reveal scalp tenderness or decreased STA pulses. There is frequent overlap of GCA with polymyalgia rheumatica, and a history of diffuse aches, pains, arthralgias, and myalgias is often elicited. The diagnosis relies on clinical suspicion and STA biopsy demonstrating granulomas with giant cells on histopathology. It is important to realize, however, that GCA can also affect the intracranial vessels (granulomatous angiitis of the CNS). Granulomatous involvement of the intracranial vessels is most often seen in the extradural space, and the inflammation can be severe enough to cause profound vessel narrowing and strokes. Most GCA-related strokes occur within the vertebral-basilar system $[134,135]$.

If giant cell arteritis is considered in the differential, treatment with high-dose corticosteroids should commence immediately and not be delayed until after the STA biopsy is performed, as the biopsy will remain positive for days after institution of corticosteroids. The survival rate for giant cell arteritis is said to be equivalent to the age-matched population [136]. There are case reports, however, of fulminant GCA and death, despite aggressive therapy with corticosteroids and other immune-modifying agents [137]. 
Systemic Vasculitides that Affect the CNS

Wegener's Granulomatosis (WG), Churg-Strauss Syndrome (CSS), and microscopic polyangiitis (MPA) are associated with the presence of anti-neutrophil cytoplasmic autoantibodies (ANCAs) and are collectively referred to as ANCAassociated vasculitides (AAVs). ANCAs are IgG antibodies directed against antigenic constituents of the azurophilic granules in neutrophils and the lysosomes of monocytes. When these antibodies are fluorescently tagged, cells may stain in either a predominantly cytoplasmic ANCA pattern or a perinuclear ANCA pattern. Most cases of cytoplasmic ANCA staining are due to antibodies directed toward proteinase 3 (PR3) and most cases of perinuclear ANCA staining are due to antibodies directed toward myeloperoxidase (MPO) [138].

AAVs are rare, with WG being the most common and CSS the least common. These disorders occur most commonly in Caucasians with the mean age of presentation being approximately 55 years of age [139]. The AAVs are systemic vasculitides that predominantly affect the lungs and the kidney, but involvement of the nervous system, including the brain, can be seen. A brief discussion of the $\mathrm{AAVs}$ thus follows.

\section{Wegener's Granulomatosis}

WG is a systemic granulomatous necrotizing vasculitis that primarily involves small blood vessels, but medium-sized vessels may also be involved. Although WG can affect almost any organ system, the respiratory tract (both upper and lower) and kidneys are most commonly involved. Most patients (80 to $90 \%$ ) with WG have ANCAs, and most of these ANCAs are directed toward PR3 [140]. The PR3 ANCAs are believed to be pathological and mediate the disease.

The incidence of WG is approximately 8 per million of the population and the prevalence 160 per million $[139,141$, 142]. Caucasians are more frequently affected than other race/ethnicities, and men are affected more often than women. Common symptoms are related to granulomatous involvement of the airway, and include bloody rhinorrhea, and rhinosinusitis. Cavitary and nodular lesions of the lungs may occur, and granulomatous invasion of the respiratory tract can lead to pulmonary hemorrhage. The PNS is affected more commonly than the CNS, and usually manifests as polyneuropathy or mononeuritis multiplex due to inflammation of the vaso nervorum. CNS involvement generally takes the form of vasculitis and meningitis; it is rare and occurs in approximately $4 \%$ of patients [143]. Granulomatous invasion of the orbit with involvement of the cranial nerves, however, is much more common [144].

To diagnosis WG, patients need to have at least 2 of the following symptoms or signs: nasal or oral inflammation, an abnormal chest radiograph (with nodules, fixed infiltrates, or cavities), an active urine sediment (with microhematuria or red cell casts), granulomatous inflammation and/or necrotizing vasculitis on tissue biopsy, and a positive enzyme immunoassay for antibodies to PR3 [145]. Once diagnosed, induction therapy for treatment of WG usually consists of parenteral corticosteroids and cyclophosphamide [146]. In a recent study in which all patients were treated with highdose corticosteroids to induce remission, rituximab was shown to be as good as cyclophosphamide for treating ANCA-associated vasculitides and better than cyclophosphamide for patients with relapsing-remitting disease [147, 148]. There are insufficient data to recommend IVIG for treating WG [149]. Long-term maintenance therapy may be achieved with a variety of immunomodulatory drugs, including methotrexate and azathioprine [150]. The survival rate for patients with WG is estimated to be 74 to $91 \%$ at 5 years $[136,151]$.

\section{Microscopic Polyangiitis}

Necrotizing and crescentic glomerulonephritis and pulmonary capillaritis are common features of MPA. Because of the capillary inflammation, lung involvement usually manifests as diffuse pulmonary hemorrhage leading to respiratory insufficiency [152]. The ANCAs in MPA are usually directed toward MPO [140]. The incidence of MPA is approximately 4 per million of the population and the prevalence is 94 per million [139, 142]. As in WG, neurological involvement in MPA usually manifests as peripheral neuropathy and mononeuritis multiplex [153]. Involvement of the CNS is quite rare, but both ischemic and hemorrhagic strokes are reported [154-158].

For active disease, induction therapy with corticosteroids and cyclophosphamide is standard care, although methotrexate and azathioprine are reasonable alternatives for long-term maintenance therapy [146, 150]. In a recent study in which all patients were treated with high-dose corticosteroids to induce remission, rituximab was shown to be as good as cyclophosphamide for treating AAVs and better than cyclophosphamide for patients with relapsingremitting disease $[147,148]$. The survival rate for MPA is reported to be 45 to $76 \%$ at 5 years $[136,151]$.

\section{CSS}

CSS is the rarest of the necrotizing small-vessel vasculitides, with an incidence of roughly 2 per million of the population with a prevalence 14 per million [139, 142]. CSS is characterized by asthma, lung infiltrates, extravascular necrotizing granulomas, and hypereosinophilia. Similar to WG, granulomatous involvement of the respiratory tract is seen, but in CSS the inflammatory process is characterized by eosinophils. 
ANCA positivity is seen in approximately $40 \%$ of patients with CSS and MPO antibodies predominate [140, 159].

As for the other AAVs, the most common neurological manifestation of CSS are neuropathy and mononeuritis multiplex with the peroneal nerve most commonly being involved $[160,161]$. CNS involvement is seen in approximately 6 to $8 \%$ of patients with CSS and cerebral infarction, as well as intracerebral and subarachnoid hemorrhage being reported [160-162]. Patients with active disease, especially with neurological involvement, should undergo induction therapy with corticosteroids and cyclophosphamide [146]. Rituximab has also been reported to improve outcome in both patients with and without CNS involvement $[163,164]$. The survival rate for CSS is reported to be 60 to $97 \%$ at 5 years $[136,151]$.

Venous Vasculitides

\section{Behçet's Disease}

Behçet's is a chronic relapsing-remitting disorder that tends to affect individuals of Eastern, Middle Eastern, and Mediterranean descent. The prevalence in Turkey ranges from 200 to 4,210 per million, whereas the prevalence in other European countries is only 24 per million [165]. Onset is generally in the third to fifth decades of life; men are affected more often than women and tend to have a worse outcome [166, 167]. The vascular inflammation in Behçet's primarily affects the venous system. The classic presentation of Behçet's is that of recurrent oral ulcers. Other characteristic findings include genital ulcers, uveitis, skin lesions (erythema nodosum, pseudofoliculitis, papulopustular lesions, acneiform nodules), and pathergy (development of skin lesions with minor trauma) [168]. The diagnosis of Behçet's is made entirely on clinical grounds, as there are no blood tests, imaging studies, or pathological studies that are pathognomonic.

Behçet's is a presumed autoimmune disease that is triggered by an environmental or infectious agent in immunologically predisposed individuals. Neurological complications of Behçet's occur in approximately $10 \%$ of patients, which are more commonly seen in men and tend to occur after several years of having the disease $[166,167]$. Most patients have parenchymal involvement of the brain due to inflammation of the small veins [166]. The brainstem is commonly involved, but other brain regions, as well as the spinal cord, may also be involved [169-171]. Aseptic meningitis also occurs [172]. In addition to inflammatory pathology in the brain, patients with Behçet's are prone to the development of cerebral vein thrombosis (CVT). The reported incidence of CVT in patients with Behçet's varies, but is roughly 3 per 1,000 person years [173].

The consensus among physicians who commonly treat Behçet's is that therapy should start with parenteral corticosteroids followed by a slow taper of oral corticosteroids.
However, there are an accumulating number of publications reporting successful therapy with inflixamab (monoclonal antibody directed against TNF- $\alpha$ ) and other biologics [174, 175]. For patients who develop CVT, anticoagulation is required, even in patients with hemorrhagic infarction [176]. The mortality in Behcet's occurs almost exclusively in men and is nearly 3 times that of age-matched controls [177]. Extracranial large vessel involvement is the leading cause of death in Behcet's, although CNS involvement is also a common causes of death [177].

Nonvasculitic Systemic Inflammatory Disorders that Affect the Nervous System

\section{Sarcoidosis}

Sarcoidosis is a systemic disorder that can affect multiple different organ systems. The etiology of sarcoid is unknown, but it is presumed to be related to an immune response toward an unidentified antigen. Sarcoid affects African-Americans more commonly than Caucasians with the incidence in North America estimated to be and 350 to 800 per 1 million African Americans and 30 to 100 per 1 million Caucasians of the population [178]. Females are affected more often than males [178].

Sarcoid is often referred to as the great imitator as it can masquerade as a number of other diseases. Tuberculosis should always be in the differential for sarcoid and must always be considered prior to institution of immunomodulatory therapy. Somewhere between $5 \%$ and $15 \%$ of patients with sarcoid will develop neurological complications, and the estimated incidence of neurosarcoid is approximately 10 per million of the population $[179,180]$. In most patients with neurosarcoid, the neurological disease is the presenting manifestation of sarcoid [179-181]. The neurological involvement can take the form of distal symmetric neuropathy and mononeuritis multiplex to basilar meningitis, granulomatous mass lesions, seizures, and endocrine dysfunction. Headaches and visual complaints are the most common presenting symptoms [180]. Cranial neuropathies occur in up to $75 \%$ of patients and most commonly involve the optic nerve, although involvement of the facial nerve is considered classic [179, 180, 182]. Endocrine abnormalities are common in sarcoid and are related to the fact that it tends to involve the hypothalamus and pituitary [183]. Typical findings include diabetes insipidus, adrenal insufficiency, and amenorrhea-galactorrhea syndrome [183]. Myelopathy may occur due to transverse myelitis or granulomatous invasion of the spinal cord itself or of the intradural or extradural space $[83,184]$. Cases of a GBS-like illness associated with sarcoid have also been reported [185].

Because of the wide range of neurological problems that can occur with neurosarcoid, it is likely that some of these 
problems at some point in time in the patients with sarcoid will be seen in the neurological ICU. Neuromuscular weakness resembling GBS may necessitate ventilatory assistance, whereas patients with intrinsic lung disease from their sarcoid may require respiratory assistance while being evaluated for less severe neurological problems. Emergent neurosurgical intervention may also be needed for obstructive hydrocephalus, due to space-occupying granulomas and communicating hydrocephalus due to involvement of the arachnoid granulations $[186,187]$. Sarcoid also affects the heart in up to $25 \%$ of patients with sarcoidosis and may manifest as left ventricular dysfunction with congestive heart failure, as well as potentially life-threatening arrhythmias due to granulomatous involvement of the conduction system [188].

Magnetic resonance Imaging in patients with neurosarcoid may show enhancement of the meninges and cranial nerves, enhancing brain lesions, nonspecific white matter changes, and hydrocephalus $[180,189]$. The presence of an enhancing suprasellar mass should always raise the suspicion of sarcoidosis. CSF analysis may show elevated protein, pleocytosis, and OCBs [180]. Elevated CSF angiotensin-converting enzyme levels appear to be specific, but not very sensitive for sarcoid [190]. Biopsy is a mainstay of the diagnostic evaluation, and the pathologic hallmark of sarcoidosis is a noncaseating granuloma, which consists of a collection of centrally organized macrophages and epitheliod cells encircled by lymphocytes.

Standard induction therapy for active sarcoid is high-dose parenteral corticosteroids [180]. A variety of immunosuppressive agents have been used for long-term maintenance therapy, including cyclophosphamide and azathioprine [180, 182]. Successful treatment with infliximab, MMF, and rituximab has been reported [191-194]. Hydroxychloroquine has been reported to stabilize symptoms [195]. The prognosis in neurosarcoid is unclear, given the rarity of the condition and the lack of good epidemiological data. Overall, the mortality from sarcoid appears to be increasing with the duration of time, but much of this appears to be related to pulmonary involvement [196]. Myelopathy portends a poor outcome [180].

\section{Sjögren s Syndrome}

Sjögren's syndrome is clinically characterized by keratoconjunctivitis sicca (dry eyes) and symptomatic xerostomia (dry mouth). These symptoms result from involvement of the lacrimal and salivary glands. Pulmonary involvement is also common, affecting $\leq 50 \%$ of patients, but it is generally mild [197]. Sjögren's syndrome affects women up to 9 times more often than men $[198,199]$. The incidence is estimated to be 40 to 50 per million of the population in Europe, with a prevalence of 2000 to 30,000 per million [200]. Sjögren's syndrome can affect both the PNS and the CNS, and $\leq 60 \%$ or more patients with Sjögren's syndrome will develop neurological symptoms, although it is largely due to cryoglobulins and anti-nuclear antibodies (anti-SSA and antiSSB) [198]. PNS involvement is characterized by sensory polyneuropathy and mononeuritis multiplex [198]. CNS manifestations occur in $6 \%$ to $25 \%$ of patients with Sjögren's syndrome, depending on the study and the definitions used, and these include encephalopathy, aseptic meningitis, optic neuritis, and MS-like disease [198, 201, 202]. Involvement of the CNS is more likely in patients with lung involvement [201]. Although most of the neurological manifestations of Sjögren's syndrome are not severe enough to warrant ICU admission, acute myelopathy can occur and potentially necessitate ventilatory support [203, 204]. Tumefactive brain lesions are also reported in Sjögren's syndrome [205, 206].

The diagnosis of Sjögren's is made in the appropriate clinical setting (dry eyes, dry mouth) in patients who have anti-SSA (Ro) and anti-SSB (La) antibodies, although seronegative Sjögren's is frequently described in patients with CNS involvement [207-209]. Salivary gland scintigraphy or biopsy of the salivary glands may also aid in the diagnosis [210]. The preferred treatment for Sjögren's syndrome who have neurological involvement is high-dose pulse corticosteroids [211]. Other immunosuppressants, such as cyclophosphamide, may be considered in patients who fail to response to corticosteroids, as an adjunct to corticosteroids or as a long-term alternative to corticosteroids. Rituximab has also been used with success [212]. There are also reports of plasmapheresis and IVIG use for the treatment of Sjögren's-related neuropathy $[213,214]$. Despite the female predominance in the occurrence of Sjögren's syndrome, death is more common in men [214]. Patients with Sjögren's syndrome are at increased risk of developing malignancies, especially lymphoma $[215,216]$.

\section{Neuropsychiatric Systemic Lupus Erythematosis}

Neuropsychiatric systemic lupus erythematosis (NPSLE) tends to occur at the time of diagnosis with SLE or within the first year after diagnosis with SLE. Patients with NPSLE generally have anti-nuclear antibodies, as well as antibodies to extractable nuclear antigens and double-stranded DNA. Anti-phospholipid antibodies are also common in SLE. NPSLE may present with an array of behavioral abnormalities, as well as with headache, seizures, chorea, aseptic meningitis, transverse myelitis, neuropathy (both cranial and peripheral), and strokes [217]. Transverse myelitis occurs in about $2 \%$ of patients with SLE $[81,218]$.

It is important to realize that vasculitis is rare in SLE and that most vascular complications are related to thrombosis $[219,220]$. The absence of vasculitic changes is particularly striking in NPSLE [221]. The management of NPSLE depends on whether the symptoms are believed to be a 
manifestation of the underlying autoimmune disorder or whether they are believed to be ischemic, resulting from the thrombotic manifestations associated with anti phospholipid antibodies. When the symptoms are believed to be secondary to inflammation, corticosteroids and other immunosuppressive therapies, including cyclophosphamide, are indicated [222-224].

\section{Antiphospholipid Antibody Syndrome}

Antiphospholipid antibody syndrome (APS) is an acquired thrombophilia associated with a heterogeneous group of antibodies to a variety of phospholipids. APS is defined by the occurrence of venous or arterial thrombosis and recurrent fetal losses in the presence of antiphospholipid antibodies. Catastrophic APS is a potentially life-threatening condition, in which patients evidence multi-organ involvement for a very short time period (less than 1 week), and there is histological evidence of multiple small vessel occlusions, as well as laboratory confirmation of antiphospholipid antibodies (usually in high titer) [225]. Mortality approaches $50 \%$ [225], and although $<1 \%$ of patients with APS develop this complication, its high mortality rate demands that clinicians be able to recognize the syndrome and treat it appropriately. Precipitating factors for catastrophic APS include surgery, infections, and withdrawal of anticoagulation [226].

Strokes (both hemorrhagic and ischemic) are a common manifestation of APS and the most frequent cause of death, followed by cardiac issues and infection [226, 227]. Analysis of prognostic variables show that patients with SLE have higher mortality with catastrophic APS than those without [226]. Anticoagulation of patients with catastrophic APS is imperative. Aggressive immune modulating therapies are also advocated and include parenteral corticosteroids, along with adjunctive therapy-like plasmapheresis or IVIG [228, 229]. With early recognition of catastrophic APS and institution of these therapies, reports suggest that mortality has decreased by approximately $20 \%$ to $30 \%$ [226].

\section{Autoimmune Encephalopathies}

A number of autoimmune encephalopathies have been described along the years. In some instances there is a clear association between the immune response to a given antigen and the encephalopathy, whereas in other cases the antigens identified as the target of the autoimmune response may merely reflect the propensity for autoimmunity and are not responsible for the symptoms. It is very clear that malignancies can trigger an immune response that cross reacts with self-antigens, but in many instances, patients do not have evidence of malignancy and the triggers are unknown.

\section{Limbic Encephalitis}

Limbic encephalitis was originally identified as a paraneoplastic disorder related to antibodies directed against onconeuronal targets (including $\mathrm{Hu}, \mathrm{Ma} 2, \mathrm{CV} 2 / \mathrm{CRMP} 5$, amphiphysin). More recently, however, limbic encephalitis has been recognized to occur in patients without cancer and a variety of pathologic antigenic targets have been identified. Antibodies to voltage-gated potassium channels (VGKCs) were identified in a number of patients with non-paraneoplastic limbic encephalitis, but further studies have shown that the real antigens in these patients are leucine-rich glioma inactivated 1 , contactinassociated protein-like 2, and contactin-2, all of which are associated with VGKCs [230, 231]. The spectrum of autoantigens associated with in limbic encephalitis, however, continues to expand, and now includes the N-methyl-D-aspartate receptor (NMDAR), the AMPA receptor, the GABA = gamma-aminobutyric acid receptor, and glutamic acid decarboxylase [232-235]. It is quite likely that many other pathologic autoantigens will be identified.

Symptom onset in limbic encephalitis is generally subacute and characterized by behavioral changes and seizures. Imaging should show involvement of the limbic system and the CSF evidence of inflammation. Idiopathic limbic encephalitis may be suggested by the presence of high titers of VGKC antibodies, although this finding is not specific as patients with paraneoplastic limbic encephalitis may occasionally have high serum titers of VGKCs as well [236]. Patients with a clinical diagnosis of limbic encephalitis should be screened for potential malignancies [237].

For patients with paraneoplastic limbic encephalitis, treatment should be directed at removal of the tumor. For noncancer-related limbic encephalitides, immunomodulatory therapies, such as corticosteroids, plasmapheresis, and IVIG have all been used with success [234, 238]. As opposed to NMDAR antibody encephalitis, outcome in limbic encephalitis is generally better in patients without an identified tumor [239].

\section{NMDAR Antibody Associated Encephalitis}

NMDAR antibody associated encephalitis is one of the more common autoimmune encephalitides. Similar to the other limbic encephalitides, it was first described to occur in association with tumors, specifically in young women with ovarian teratomas [240, 241]. NMDAR antibody associated encephalitis is now known to occur in patients without tumors as well. The antibodies are directed against the NR1 subunit of the NMDA receptor [242]. The clinical spectrum of NMDAR antibody associated encephalitis ranges from memory disturbances and movement disorders to seizures (including status epilepticus), catatonia, and 
coma [243, 244]. Hypoventilation may necessitate mechanical ventilation [245]. Dysautonomia is common and can been severe enough to require cardiac pacing $[245,246]$. The MRI is often abnormal and the electroencephalography is almost uniformly abnormal in patients with NMDAR antibody associated encephalitis. CSF analysis usually reveals a mild lymphocytic pleocytosis and occasionally shows increased protein and OCBs. Definitive diagnosis depends on identifying the pathologic NMDAR antibodies [245].

Immunomodulatory therapies, such as corticosteroids, plasmapheresis, and IVIG have all been used with success in the treatment of NMDAR antibody associated encephalitis, and outcome appears to be better in patients in whom teratomas are found and removed [245]. A combination of rituximab and cyclophosphamide is typically used when treatment with plasmapheresis or IVIG do not result in to sufficient improvement [243].

\section{Steroid Responsive Encephalopathy Associated with Autoimmune Thyroiditis}

Steroid responsive encephalopathy associated with autoimmune thyroiditis (SREAT), also known as Hashimoto's encephalopathy, is rare, poorly understood, and likely underdiagnosed. The literature is comprised solely of case reports. Neuropsychiatric symptoms are common and memory loss is nearly universal in patients with SREAT. Seizures may occur as can strokes or stroke-like episodes [247-249]. Tremor and myoclonus are frequently seen on clinical examination $[250,251]$. Hypersomnolence is also seen and can progress to coma [252]. Thyroid hormone concentrations (T3, T4, thyroid-stimulating hormone) may be normal [253]. Antibodies to thyroperoxidase and thyroglobulin are suggestive of SREAT in the appropriate clinical setting [254]. These antibodies, however, are not believed to be pathogenic. The exact mechanism of disease is unknown, but is speculated to by either vasculitis or direct neuronal/glial recognition by autoantibodies (but not anti-thyroperoxidase or ant-thyroglobulin antibodies) $[254,255]$. The CSF may show a slight pleocytosis and mild-moderate elevation of protein. Approximately half of the patients with SREAT have focal or diffuse nonenhancing abnormalities on MRI. The MRI can also reveal acute infarcts, raising the specter of vasculitis [256]. The differential for SREAT includes viral encephalitis, Creutzfeldt-Jakob disease, and other forms of dementia [251, 257-261].

As the name suggests, SREAT is generally steroid responsive, yet review of the literature suggests that approximately only $50 \%$ of patients respond to corticosteroids. Plasmapheresis has been used in some patients and there are reports of successful treatment with IVIG and rituximab [262-266].

\section{Rasmussen's Encephalitis}

Rasmussen's encephalitis (RE) is a rare inflammatory disorder that affects primarily children, but can also affect adults [267271]. The clinical presentation is that of refractory seizures with cognitive decline, hemispheric atrophy, and progressive hemiparesis; young children tend to progress much more rapidly than young adults. A serendipitous finding that rabbits immunized with the glutamate receptor GluR3 developed a syndrome similar to RE, which led to the identification of antibodies to GluR3 in the serum of many patients with RE [272]. Despite the presence of GluR3 antibodies in the serum, histology suggests that RE may be a T-cell mediated disease [273]. The diagnosis of RE is a clinical one, as the imaging and EEG findings are not specific, and the presence of GluR3 antibodies is neither specific nor sensitive [274]. Pathology generally shows changes consistent with chronic encephalitis (in various stages of active inflammation), findings which are also nonspecific.

Symptomatic treatment of RE includes the use of anticonvulsants. Given the presumed contribution of the immune system to the pathogenesis of RE, a number of immunomodulatory therapies, including plasmapheresis, IVIG, and corticosteroids have been used to treat the disorder; plasmapheresis or IVIG are usually recommended [275, 276]. These treatments appear to reduce the frequency of seizures, but are seldom curative. Definitive treatment is still considered to be hemispherectomy [277, 278].

\section{Disorders of the Neuromuscular Transmission} (Including Channelopathies)

\section{Myasthenia Gravis}

Myasthenia gravis (MG) is perhaps the best characterized autoimmune disease that affects the nervous system. Patients present with fatigable muscle weakness. MG is most commonly related to antibodies to the acetylcholine receptor (AChR), although other pathologies have also been described. Approximately 70 to $95 \%$ of patients with $\mathrm{MG}$ will have detectable AChR antibodies [279]. The annual incidence of MG is estimated to be 5 per million persons of the population with a the prevalence of 78 per million person years [280]. The incidence of MG is much higher in women during the first 5 decades of life, but then it becomes higher in men during the subsequent 3 decades [281]. Of the patients with AChR seronegative MG, many have antibodies to muscle specific tyrosine kinase (MuSK) [282, 283]. The patients with anti-MuSK antibodies tend to be predominantly female and present in their 40s with ocular and bulbar symptoms [284].

The diagnosis of MG is based on appropriate history and examination (fatigable muscle weakness) and diagnostic 
studies, including assays for AChR or MuSK antibodies. Electrical studies are also valuable in making the diagnosis of MG. With repetitive nerve stimulation (at 2 to $3 \mathrm{~Hz}$ ) there is a progressive decrement in the amplitude of the compound muscle action potential. The decremental response is most reliably found in clinically weak muscles and may not be seen at all in patients with predominantly oculobulbar weakness. Single fiber electromyography (EMG) is more sensitive than repetitive nerve stimulation, and abnormalities are seen in virtually all patients with MG in whom the weak muscles can be studied.

Myasthenic crisis is defined as acute weakness with inability to breathe or swallow; approximately $15 \%$ to $20 \%$ of patients with MG will suffer a crisis at some point during their illness $[285,286]$. Myasthenic crisis is the one of most common causes of neuromuscular respiratory failure seen in the ICU [90]. Therapeutic management relies on the combination of acetylcholinesterase inhibitors and immunomodulation. The acetylcholinesterase inhibitors can improve strength quickly, whereas immunomodulation takes time. Corticosteroids are often avoided in MG as they can potentially exacerbate weakness following initial administration. For patients admitted to an ICU in crisis, however, transient mild worsening of weakness is a minor concern. Most guidelines, therefore, suggest that high-dose parenteral corticosteroids be given to patients in crisis along with another form of therapy, such as plasmapheresis or IVIG. There are no adequate RCTs evaluating the role of plasmapheresis versus conservative therapy in patients with MG, but there are several case series which seem to suggest that plasmapheresis does have a short-term benefit in patients with myasthenic crisis [23, 287]. For exacerbations of MG, there is a single RCT showing benefit to treatment with IVIG and another study that showed IVIG and plasmapheresis to be of similar efficacy [288]. A review of the Nationwide Inpatient Sample database for the years 2000 to 2005 shows that the use of IVIG has been steadily increasing and that adjusted mortality and complication rates were similar for patients treated with plasmapheresis and IVIG [289]. For patients with anti-MuSK antibodies, plasmapheresis may be superior to IVIG [284]. A discussion regarding ventilator management in patients with neuromuscular disorders is beyond the scope of this chapter, but the general consensus is that during the acute crisis for which immunomodulatory therapy (i.e., plasmapheresis or IVIG) is being given, patients should be allowed to "rest" on full ventilatory support.

Mortality for patients with MG is 0.1 to 0.9 per million per year [280]. As might be expected, the mortality rate in patients with crisis is much higher, and approximately $4 \%$ of patients will die during hospitalization for myasthenic crisis [289]. Both older age and respiratory failure are associated with increased mortality [281, 289].

\section{Lambert-Eaton Myasthenic Syndrome}

Lambert-Eaton Myasthenic Syndrome (LEMS) was first described as a paraneoplastic syndrome associated with small cell lung cancer. It is now known to occur as a primary autoimmune disease, independent of cancer. Patients with LEMS have antibodies to the P/Q-type voltage-gated calcium channels that attack the presynaptic nerve terminal. Patients present with muscle weakness, fatigue, and autonomic dysfunction (especially dry mouth). LEMS is rare, with an incidence of 0.4 per million of the population and a prevalence of 2.5 per million [290]. Electrical studies are important for diagnosis of LEMS and show facilitation of compound motor action potentials after high frequency $(20-50 \mathrm{~Hz})$ stimulation. Clinically, patients are weak and may be either hyporeflexic or areflexic; both the weakness and hyporeflexia improve after exercise.

Patients with LEMS can present with respiratory failure [291-298]. The mainstay of treatment for LEMS is 3,4diamino pyridine, which increases the amount of acetylcholine released at the neuromuscular junction [299]. There is at least some evidence, albeit from a very small trial, that treatment with IVIG may be of benefit in patients with LEMS [299]. The usefulness of corticosteroids and plasmapheresis for the treatment of LEMS has not been assessed in RCTs.

\section{Stiff-Person Syndrome}

Antibodies to glutamic acid decarboxylase are found in the majority $(60-80 \%)$ of patients with stiff-person syndrome (SPS) [300-302]. Other autoantibodies associated with SPS include those to the GABA-A receptor, amphiphysin, and gephyrin [303-306]. Patients with progressive encephalopathy associated with limb rigidity are said to have progressive encephalomyelitis with rigidity and myoclonus (PERM) or stiff-person plus syndrome. Antibodies to the glycine receptor have been identified in patients with PERM $[307,308]$. Patients with SPS, and especially PERM, may develop respiratory failure and are at risk for sudden cardiac death [309].

SPS is rare, but there has been a single RCT demonstrating a benefit to IVIG therapy; IVIG is thus the therapy with the best available evidence [310, 311]. Because SPS is an antibody mediated disorder, it would be expected that plasmapheresis and rituximab would be reasonable treatments, and both have been used with reports of success [309, 312].

\section{Neuromyotonia}

Neuromyotonia (or Issac's syndrome) is associated with antibodies to VGKCs and result in hyperexcitability of the peripheral motor nerve. Patients with neuromyotonia complain 
of muscle cramps and have evidence of muscle twitching (myokymia and neuromyotonia), muscle hypertrophy, muscle weakness, and hyperhidrosis on examination. If central features are present (anxiety, memory problems, personality changes, sleep disturbance), the disorder is referred to as Morvan's syndrome. Patients with Morvan's syndrome may develop agrypnia excitata, which is characterized by autonomic activation, persistent insomnia, and generalized overactivity with inability to generate slow wave sleep [313, 314]. Agrypnia excitata is extremely rare and can be life-threatening.

EMG shows spontaneous and continuous motor unit discharges, fasciculations, and myokymic discharges. The phenotype of the disorder caused by VGKCs appears to be related to the component of the $\mathrm{K}^{+}$channel to which the antibody is directed. For instance, antibodies to contactinassociated protein-2 tend to be associated with limbic encephalitis, Morvan's syndrome, and Issac's syndrome, and are seen in patients with thymomas [231, 239, 315, 316]. Antibodies directed toward leucine-rich glioma inactivated 1 are associated with epilepsy and limbic encephalitis, and are seen in patients without tumors $[239,315]$.

The mainstay of therapy for patients with neuromyotonia is the use of anti-epileptic drugs that decrease nerve excitability. In addition, high-dose parenteral corticosteroids are commonly used for treating patients with acute presentations; IVIG and plasmapheresis have also been used with reports of benefit [311, 317-319].

\section{Immunomodulatory Therapies}

There is an ever increasing armamentarium of drugs and antibodies available to modulate the immune response. Most of these therapies are used for chronic immunosuppression, and many take weeks to months before their biological effect is realized. We will focus only on those interventions that are commonly used in the ICU for the acute treatment of the immune-mediated neurological diseases previously described. The indications and levels of evidence for each of these interventions are summarized in Table 1 using the guidelines adopted by the American Academy of Neurology [320].

\section{Plasmapheresis}

Therapeutic plasma exchange (plasmapheresis) is an extracorporeal blood purification technique designed to remove large molecular weight particles from plasma. Blood is removed from the patient, plasma is separated from the blood's cellular elements, and is exchanged with colloid replacements (usually fresh-frozen plasma or albumin solution); the cellular blood components are returned to the patient. The principle mechanism of action in plasmapheresis is thought to be the removal of pathogenic autoantibodies, as well as macromolecular immune complexes, inflammatory cytokines, and other mediators from the intravascular space. Reduction of serum immunoglobulin levels and pathogenic antibodies to gangliosides in GBS and to the acetylcholine receptor and muscle specific kinase in patients with MG is documented [321, 322]. The mechanism of action of plasmapheresis, however, is likely more complex than simple physical removal of antibodies from the blood. Multiple effects on the cellular components of the immune system have also been described. Plasmapheresis induces the proliferation of lymphocytes in patients with both MS and GBS, perhaps due to removal of an unknown lymphocyte suppression factor [323, 324]. It is felt that the enhanced proliferation could augment the action of immunosuppressive drugs that target actively dividing lymphocytes. A variety of other effects of plasmapheresis on immune function have been postulated [325-327].

For the treatment of acute exacerbations of most autoimmune neurological conditions, a series of plasma exchanges $(50 \mathrm{~mL} / \mathrm{kg}$ or $1.0-1.5$ plasma volumes per procedure per day) for a 1 - to 2 -week period of time is recommended [328]. The optimal number of plasmapheresis treatments for most disorders is unclear, but the usual practice is approximately 5 treatments over approximately 10 days. Treatments every other day (as opposed to daily) are probably more effective in reducing the antibody levels, as it allows for redistribution of extravascular immunoglobulins into the intravascular space. The effects of plasmapheresis are of limited duration as the autoantibodies removed by plasmaphedresis are quickly replaced by synthesis of new autoantibodies in the face of ongoing antigenic stimulation. Repeated plasmapheresis treatments are thus required to achieve the desired effects [329].

As previously outlined and summarized by the Therapeutics and Technology Assessment Subcommittee of the American Academy of Neurology, plasmapheresis is of proven benefit for the treatment of AIDP/GBS and may also be of value for the treatment of MS relapses [23]. Data to support the use of plasmapheresis for the treatment of MG, $\mathrm{NMO}$, and other fulminant demyelinating disorders are insufficient, although it is commonly used [23].

Plasmapheresis is only available in specialized centers and is associated with risks. Adverse reactions can occur due to the need for central venous access (infection, thrombosis, and pneumothorax). Hypotension may occur in up to $20 \%$ of patients undergoing plasmapheresis, and certain filtration techniques can cause hemolysis [330]. Unstable hemodynamics, coagulopathy, sepsis, and problems with vascular access can preclude the use of plasmapheresis. Repeated treatments with albumin replacement may lead to depletion of coagulation factors and immunoglobulins, increasing the risk of bleeding and infections. If fresh-frozen plasma is used as replacement fluid, there is a risk (albeit very low) of transmission of viruses, such as hepatitis $\mathrm{C}$ virus or 
Table 1 Important immunological treatments in the neurological ICU

\begin{tabular}{|c|c|c|c|c|c|}
\hline Treatment & Plasmapheresis & IV Corticosteroids & IVIG & Rituximab & Cyclophosphamide \\
\hline \multirow{5}{*}{$\begin{array}{l}\text { Main indications } \\
\text { (class of evidence } \\
\text { and level of } \\
\text { recommendation) }\end{array}$} & AIDP/GBS (IA) & $\begin{array}{l}\text { Acute CNS } \\
\text { demyelination (IB) }\end{array}$ & AIDP/GBS (IA) & WG (FDA-approved) & $\begin{array}{l}\text { Acute CNS } \\
\text { demyelination } \\
\text { (IIaC) }\end{array}$ \\
\hline & CIDP (IB) & $\begin{array}{l}\text { myasthenia gravis } \\
\text { (IIbC) }\end{array}$ & myasthenic crisis (IA) & MPA (FDA-approved) & $\begin{array}{l}\text { primary CNS } \\
\text { vasculitis (IIbC) }\end{array}$ \\
\hline & $\begin{array}{l}\text { acute CNS } \\
\text { demyelination (IB) }\end{array}$ & $\begin{array}{l}\text { primary CNS } \\
\text { vasculitis (IIbC) }\end{array}$ & $\begin{array}{l}\text { acute CNS } \\
\text { demyelination (IIB) }\end{array}$ & MS (IIB) & $\begin{array}{l}\text { NMDAR } \\
\text { encephalitis } \\
\text { (IIIU) }\end{array}$ \\
\hline & \multirow[t]{2}{*}{$\begin{array}{l}\text { myasthenic } \\
\text { crisis (IIIU) }\end{array}$} & $\begin{array}{l}\text { Hashimoto } \\
\text { encephalopathy/ } \\
\text { SREAT (IaB) }\end{array}$ & $\begin{array}{l}\text { limbic encephalitis } \\
\text { (IIA) }\end{array}$ & NMO (IIIU) & \multirow[t]{2}{*}{$\begin{array}{l}\text { Hashimoto } \\
\text { encephalopathy/ } \\
\text { SREAT (IIBC) }\end{array}$} \\
\hline & & $\begin{array}{l}\text { limbic encephalitis } \\
\text { (IIbC) }\end{array}$ & & $\begin{array}{l}\text { NMDAR encephalitis } \\
\text { (IIIU) }\end{array}$ & \\
\hline Typical dosing & $\begin{array}{l}5 \text { Treatments every } \\
\text { other day with } \\
1-1.5 \times \text { plasma } \\
\text { volume each }\end{array}$ & $\begin{array}{l}\text { Methylprednisolone } \\
1 \text { g i.v. } \times 3-5 \text { days }\end{array}$ & $\begin{array}{l}0.4 \mathrm{~g} / \mathrm{kg} \text { i.v. Daily } \times 5 \\
\text { days (i.e., } 2 \mathrm{~g} / \mathrm{kg} \\
\text { total) }\end{array}$ & $\begin{array}{l}375 \mathrm{mg} / \mathrm{m}^{2} \text { i.v. Once } \\
\text { weekly for } 4 \text { weeks }\end{array}$ & $\begin{array}{l}15 \mathrm{mg} / \mathrm{kg} \text { i.v. } \\
\text { Every } 2-3 \text { weeks }\end{array}$ \\
\hline $\begin{array}{l}\text { Main side effects } \\
\text { in acute treatment }\end{array}$ & $\begin{array}{l}\text { Risks associated with } \\
\text { central line; } \\
\text { hypocalcemia, } \\
\text { hypotension, } \\
\text { coagulopathy risk } \\
\text { of FFP }\end{array}$ & $\begin{array}{l}\text { Gastric ulcers, } \\
\text { hyperglycemia, } \\
\text { hypokalemia, mood } \\
\text { instability, } \\
\text { insomnia }\end{array}$ & $\begin{array}{l}\text { Acute renal failure, } \\
\text { thrombotic events, } \\
\text { anaphylaxis infection } \\
\text { (HIV, HCV) }\end{array}$ & $\begin{array}{l}\text { Anaphylaxis infusion } \\
\text { reaction, risk of PML }\end{array}$ & $\begin{array}{l}\text { Leukopenia } \\
\text { hemorrhagic } \\
\text { cystitis, bladder } \\
\text { cancer, nausea, } \\
\text { vomiting. } \\
\text { teratogenicity }\end{array}$ \\
\hline
\end{tabular}

$\mathrm{AIDP}=$ acute inflammatory demyelinating polyneuropathy; $\mathrm{CIDP}=$ chronic inflammatory demyelinating polyneuropathy; $\mathrm{CNS}=$ central nervous system; FDA=Food and Drug Administration; FFP=fresh frozen plasma; GBS=Guillain-Barré syndrome; HCV=hepatitis $\mathrm{C}$ virus; HIV=human immunodeficiency virus; ICU=intensive care unit; IV=intravenous; $I V I G=$ intravenous immune globulin; $\mathrm{MPA}=$ microscopic polyangiitis; $\mathrm{MS}=$ multiple sclerosis; NMDAR=N-methyl-D-aspartate receptor; $\mathrm{NMO}=$ neuromyelitis optica; $\mathrm{PML}=$ progressive multifocal leukoencephalopathy; $\mathrm{RCT}=$ randomized clinical trial; SREAT $=$ steroid responsive encephalopathy; $\mathrm{WG}=$ Wegener's granulomatosis

Levels of evidence are adopted from the American Academy of Neurology guidelines [320]. Briefly, class I evidence is derived from a high-quality RCT, class II evidence is derived from a lesser quality RCT, class III evidence is derived from trials using historical controls or crossover designs, and class IV evidence is all evidence that does not meet the criteria for class I, II, or III evidence (and includes consensus, as well as expert opinion). The recommendations are categorized as level A (established to be effective, ineffective, or harmful by at least 2 class I studies), level B (probably effective, ineffective, or harmful based on 1 class I study or 2 consistent class II studies), C level (possibly effective, ineffective, or harmful, based on 1 class II study or 2 consistent class III studies), or U level (inadequate or conflicting data)

human immunodeficiency virus (HIV). Citrate infused for anticoagulation or as part of fresh-frozen plasma may lead to hypocalcemia or metabolic acidosis. Symptoms of hypocalcemia occur in 1.5 to $9 \%$ of plasmapheresis treatments and include paresthesias, muscle cramps, and, in severe cases, cardiac arrhythmias [331].

\section{Pharmaceuticals}

\section{Corticosteroids}

The anti-inflammatory effects of corticosteroids are mediated by a number of different mechanisms, including both genomic and nongenomic actions. With activation of the cytoplasmic glucocorticoid receptor, the receptor translocates to the nucleus and binds to glucocorticoid response elements in the promoter region of target genes and activates transcription (transactivation) or inhibits the transactivating function of transcription factors (transrepression), such as nuclear factor kappa-B, which is responsible for the transcription of proinflammatory genes [332]. These genomic changes require at least several hours before taking effect. More immediate effects of corticosteroids (seconds to minutes) can be seen due to multiple nongenomic mechanisms of action, although these effects are less wellunderstood. Some of the nongenomic effects include inhibition of inflammatory cytokine secretion due to decreased stability of mRNA for genes of inflammatory proteins and impairment of leukocyte adhesion, extravasation, and entry into inflamed tissue [333]. Furthermore, corticosteroids cause T-cell apoptosis and lead to a transient rise in circulating neutrophils due to accelerated release from the bone marrow and reduced migration out of the blood into inflammatory sites [334, 335].

Methylprednisolone is the most commonly used parenteral corticosteroid in the United Sates and the usual dose for treating acute neurological diseases is $500 \mathrm{mg}$ to $1,000 \mathrm{mg}$ per day for 3 to 5 days. Methylprednisolone has some 
mineralocorticoid effect, so electrolytes (particularly $\mathrm{K}^{+}$) need to be monitored daily during therapy. Dexamethasone is less commonly used than methylprednisolone for the treatment of inflammatory neurological diseases. The relative anti-inflammatory potency of dexamethasone, however, is 6 times higher than that of methylprednisolone [336]. Dexamethasone is typically given at a dose of $4 \mathrm{mg}$ IV every 6 hours. Unlike methylprednisolone, dexamethasone has purely glucocorticoid actions.

Side effects associated with high-dose parenteral corticosteroids, even short courses of therapy, include gastrointestinal ulcers, and prophylaxis with an $\mathrm{H}_{2}$ blocker or a proton pump inhibitor is recommended. Many patients will require insulin administration during treatment with corticosteroids due to hyperglycemia. The risk of deep venous thrombosis may also be increased with high-dose parenteral corticosteroids. In the ICU setting, and especially in patients requiring neuromuscular blockade, steroid-induced myopathy may occur. Finally, important neuropsychiatric side effects of high-dose corticosteroids include insomnia, mood instability (hypomania or irritability), and psychosis [337].

Chronic corticosteroid use is associated with multiple side effects; initiation of "steroid-sparing drugs" is thus considered concomitant with the use of parenteral corticosteroids as these "steroid-sparing drugs" often take weeks to months until the therapeutic effects become apparent. The side effects seen with corticosteroid therapy include obesity, diabetes, skin atrophy, disturbed wound healing, cataracts, glaucoma, and bone loss [338]. The risk of osteoporosis is dose-related and can be reduced by vitamin $\mathrm{D}$ and calcium supplementation [339]. Patients treated with chronic corticosteroids are at increased risk for infection with Pneumocystis carinii pneumonia, and prophylaxis with trimethoprim/sulfamethoxazole is often recommended [340]. Importantly, hypothalamicpituitary-adrenal axis suppression necessitates a slow taper instead of abrupt discontinuation of corticosteroids to avoid adrenal insufficiency. For patients treated with long-term corticosteroids, adrenal insufficiency should be considered in the setting of acute illness.

\section{Cyclophosphamide}

Cyclophosphamide was originally developed for the treatment of malignancies. Although cyclophosphamide is not approved by the Food and Drug Administration (FDA) for the treatment of autoimmune diseases of the nervous system, it is nonetheless used for the treatment of a number of these diseases. Cyclophosphamide is transformed in the liver into its active form, an alkylating drug that binds to DNA and interferes with cell mitosis and replication. Some of the immunosuppressive effects of this drug are likely due to the reduction in lymphocyte numbers, both B-cells and T-cells, which interfere with both cell-mediated and humoral immune responses.
Cylcophosphamide also appears to selectively suppress the activity of TH1 helper cells and enhance TH2 helper responses [341]. Furthermore, it has been shown to lead to suppression of interleukin-12 production by monocytes and dosedependent alterations in the number and function of $\mathrm{CD}^{+}{ }^{+} \mathrm{CD} 25^{+}$regulatory T-lymphocytes [342].

As a steroid-sparing agent in chronic therapy, cyclophosphamide may be given as a daily oral medication or as an intravenous infusion every few weeks. A typical dose of oral cyclophosphamide for the treatment of vasculitis is $2 \mathrm{mg} / \mathrm{kg}$ with a maximum of $150 \mathrm{mg} /$ day (adjusted dose in renal insufficiency) daily for 4 weeks [147]. Typical dosing of intravenous cyclophosphamide for the treatment of primary CNS vasculitis is $15 \mathrm{mg} / \mathrm{kg}$ every 2 to 3 weeks [343]. Data suggest that pulse doses of cyclophosphamide may be safer and better tolerated than daily oral doses [343-345]. MS is usually treated with monthly infusions of up to $1500 \mathrm{mg} / \mathrm{m}^{2}$ (with dose reductions depending on the white blood cell nadir) [342]. High-dose cyclophosphamide, at $200 \mathrm{mg} / \mathrm{kg}$ divided into 4 daily doses of $50 \mathrm{mg} / \mathrm{kg}$ followed by granulocyte colony-stimulating factor, has also been used in therapy-refractory myasthenia gravis, NMO, and rapidly progressive MS [346-349].

Important side effects of cyclophosphamide include leukopenia and hemorrhagic cystitis. The latter is thought to be caused by acreolein, a byproduct of cyclophosphamide, and hemorrhagic cystitis occurs more commonly in patients with prior dysfunction of the urinary tract system. Sodium 2mercaptoethane sulfonate (mesna) is given along with cyclophosphamide to prevent bladder injury. An increased risk of bladder cancer has been observed in patients with prolonged cyclophosphamide use, and regular screening of urine cytology is recommended [350]. The incidence of other cancers, including secondary acute leukemia and skin cancers, is also increased by cyclophosphamide use [351]. High-dose cyclophosphamide can cause acute cardiac toxicity and premature gonadal failure, especially in women. As with most anti-neoplastic agents, cyclophosphamide is teratogenic and should not be given to women who can become pregnant or to nursing mothers, because it is excreted in breast milk. Other side effects include mild alopecia, nausea, and vomiting; these side effects are dose-dependent, transient, and reversible.

\section{Biologics}

\section{Intravenous Immunoglobulin}

IVIG is a fractionated blood product from pooled plasma of several thousand donors. The main component of IVIG is $\mathrm{IgG}$, although smaller amounts of IgA and IgM antibodies, as well as other molecules such as cytokines, may also be present in IVIG and contribute to its therapeutic effects. The 
mechanisms by which IVIG exerts its therapeutic effects, however, are not fully understood. A detailed exploration of the numerous hypotheses explaining the mechanism of IVIG in autoimmune diseases is beyond the scope of this review, but can be found in previous reviews [352, 353]. One of the main effects of IVIG, however, is thought to be its inhibition of autoantibody mediated injury by increased catabolism of pathologic antibodies, interference of pathologic antibodies from binding to their targets, and prevention of complement activation [329, 354-358]. IVIG may also affect the cellular immune response by altering the interaction of T-cells with antigen presenting cells and by hastening apoptosis of autoreactive T-cells [352]. Additionally, IVIG may interfere with the differentiation, activation, and proliferation of B cells, enhance their apoptosis, and block the activity of cells that release autoantibodies [359362]. Additional mechanisms of action for IVIG have also been postulated, but by and large, the mechanism of action of IVIG remains unclear [363-365].

The only neurological disease with an FDA-approved indication for IVIG is chronic inflammatory demyelinating polyneuropathy, a disorder that rarely requires ICU admission and is not discussed in this chapter. Off-label use of IVIG, however, is widespread [366, 367]. In practice, IVIG is considered to be an alternative to plasmapheresis. The usefulness of IVIG is best proved for GBS, in which several RCTs find IVIG and plasmapheresis to be equally efficacious [368]. IVIG is also beneficial in the treatment of myasthenic crisis, an approach that is supported by a single randomized trial [369]. Results from randomized trials comparing the efficacy of IVIG and plasmapheresis in myasthenia exacerbations are equivocal [288]. In addition to the treatment of chronic inflammatory demyelinating polyneuropathy, AIDP/GBS, and MG, IVIG is often considered for the treatment of acute exacerbations of demyelinating CNS disease, such as MS, NMO, and ADEM, although no RCTs have confirmed the benefit of IVIG in any of these conditions [45, 370-375].

The dose of IVIG for the acute treatment of neurological autoimmune diseases is generally $0.4 \mathrm{~g} / \mathrm{kg}$ i.v. daily for 5 days (for a total dose of $2 \mathrm{~g} / \mathrm{kg}$ ) [328]. IVIG is usually welltolerated, with adverse reactions occurring in $<5 \%$ of patients. Common reactions include headache, chills, fever, myalgias, and noncardiac chest discomfort.[353] Self-limited aseptic meningitis is rare and typically occurs within $72 \mathrm{~h}$ of the first dose [367]. Fluid overload and hyponatremia can be seen with IVIG treatment. More serious reactions include thrombotic events, acute renal dysfunction, and anaphylactic reactions. Venous and arterial thrombotic events due to transient hyperviscosity are reported in up to $1 \%$ of patients; the risk may be limited by slower infusion rates $[376,377]$. Acute renal dysfunction is rare and more likely to occur in products stabilized with sucrose [378]. Patients with IgA deficiency appear to be at higher risk of hypersensitivity and anaphylactic reactions to
IVIG, and some centers will rule out IgA deficiency prior to initiation of therapy [379]. Finally, because IVIG is isolated from pooled human plasma, infection with HIV, hepatitis B virus, or hepatitis $\mathrm{C}$ virus is a theoretical concern.

\section{Rituximab}

Rituximab is a genetically engineered human/murine chimeric monoclonal antibody that is directed against the transmembrane protein $\mathrm{CD} 20$, which is expressed on pre-B-cells in the bone marrow as well as mature B-cells, but not antibody secreting plasma cells. Treatment with rituximab thus selectively depletes B-lymphocytes, but not plasma cells [380]. The depletion of B-cells occurs through a combination of antibody dependent cell-mediated toxicity and complement-mediated cytotoxicity, and lasts for approximately 6 months [381].

Despite the fact that CD20 is not present on antibodyproducing plasma cells, a reduction of autoantibodies is seen following treatment with rituximab likely due to the depletion of $\mathrm{CD} 27^{+}$memory B-cells, the precursors of the shortlived plasma cells $[381,382]$. In addition to reduced antibody production, rituximab has been shown to reduce TNF$\alpha$ production by macrophages and increase the frequency of regulatory $\mathrm{CD}^{+} \mathrm{CD} 25$ (high) T-cells and $\mathrm{CD} 56$ (bright) NK cells $[383,384]$.

Rituximab is approved by the FDA for the treatment of malignancies (non-Hodgkin's B-cell lymphoma and chronic lymphocytic leukemia), as well as autoimmune disorders, including rheumatoid arthritis (as an adjunct to methotrexate), and WG and MPA (as an adjunct to corticosteroids). In addition, rituximab is increasingly being used "off-label" to treat a variety of immunologically mediated neurological diseases, particularly those thought to be secondary to the production of autoantibodies. In relapsing-remitting MS, a placebo-controlled blinded study of 104 patients showed a reduction in relapse rate in patients treated with rituximab, and in a subgroup of patients with primary-progressive MS $<51$ years of age and with active gadolinium-enhancing lesions on MRI, treatment with rituximab led to slowing of disease progression compared to placebo [385, 386]. Smaller noncontrolled trials or case reports exist for NMO, MG, Sjögren's syndrome, NMDAR encephalitis, and other antibody mediated neurological diseases.

The dose of rituximab approved for the treatment of WG and MPA is $375 \mathrm{mg} / \mathrm{m}^{2}$ once weekly for 4 weeks. For rheumatoid arthritis, the dosing regimen is 2 doses of $1000 \mathrm{mg}$ IV each separated by 2 weeks and repeated every 6 months. The side effect profile of rituximab is relatively favorable, although mild-to-moderate infusion-related reactions can be observed. Infusion reactions may consist of flulike symptoms, such as fever, rigors, and headache. Hypotension has also been described and antihypertensive 
medications are usually held on the day of infusion. Rashes and anaphylactic reactions may also seen, but can be prevented by premedication with antihistamines (and occasionally methylprednisolone). These reactions typically occur with the first infusion [387].

A potentially more serious concern related to the use of rituximab is the occurrence of progressive multifocal leukoencephalopathy (PML), a devastating infectious disease that results in demyelination of the brain. PML is caused by reactivation of JC virus, which is found in a large proportion of the healthy population. In patients with a compromised immune system due to malignancy, HIV infection or certain immunomodulatory drugs, most notably in natalizumab (a monoclonal antibody used in the treatment of MS and Crohn's disease), the JC virus becomes active and demyelinates the brain. Recent case reports suggest that therapy with rituximab is also associated with an increased risk of PML [388, 389].

\section{Conclusions}

In this chapter, we attempted to summarize the most common inflammatory diseases that affect the nervous system. It is impossible in the space provided to discuss all such diseases that could affect either the CNS or PNS. The theme that emerges for most of the disease entities discussed in this article is that treatment of acute presentations should use drugs/interventions that have an immediate onset of action, such as corticosteroids, plasmapheresis, and IVIG. Another theme that emerges is that diseases for which antibodies are thought to be pathologic, plasmapheresis and treatment with rituximab appear to be logical therapeutic strategies. Because many of the disorders discussed are quite rare, RCTs would be nearly impossible to perform, so recommendations for therapy are based on case series and anecdotal reports.

Required Author Forms Disclosure forms provided by the authors are available with the online version of this article.

\section{References}

1. Koch-Henriksen N, Sorensen PS. The changing demographic pattern of multiple sclerosis epidemiology. Lancet Neurol 2010;9:520-532.

2. Bronnum-Hansen H, Stenager E, Hansen T, Koch-Henriksen H. Survival and mortality rates among Danes with MS. Int MS J 2006; 13:66-71.

3. Kingwell E, van der Kop M, Zhao Y, et al. Relative mortality and survival in multiple sclerosis: findings from British Columbia, Canada. J Neurol Neurosurg Psychiatry 2011. doi:10.1136/jnnp2011-300616.
4. Sumelahti ML, Hakama M, Elovaara I, Pukkala E. Causes of death among patients with multiple sclerosis. Mult Scler 2010;16:1437-1442.

5. Hader WJ. Disability and survival of multiple sclerosis in Saskatoon, Saskatchewan. Can J Neurol Sci 2010;37:28-35.

6. Grytten Torkildsen N, Lie SA, Aarseth JH, Nyland H, Myhr KM. Survival and cause of death in multiple sclerosis: results from a 50-year follow-up in Western Norway. Mult Scler 2008;14:1191-1198.

7. Moldovan IR, Rudick RA, Cotleur AC, et al. Longitudinal singlecell cytokine responses reveal recurrent autoimmune myelin reactivity in relapsing - remitting multiple sclerosis patients. Mult Scler 2005;11:251-260.

8. Lalive PH, Menge T, Delarasse C, et al. Antibodies to native myelin oligodendrocyte glycoprotein are serologic markers of early inflammation in multiple sclerosis. Proc Natl Acad Sci U S A 2006;103:2280-2285.

9. Lucchinetti CF, Brueck W, Rodriguez M, Lassmann H. Multiple sclerosis: lessons from neuropathology. Semin Neurol 1998;18:337349.

10. Aktas O, Kieseier B, Hartung HP. Neuroprotection, regeneration and immunomodulation: broadening the therapeutic repertoire in multiple sclerosis. Trends Neurosci 2010;33:140-152.

11. Bates D. Treatment effects of immunomodulatory therapies at different stages of multiple sclerosis in short-term trials. Neurology 2011;76:S14-S25.

12. Conway D, Cohen JA. Combination therapy in multiple sclerosis. Lancet Neurol 2010;9:299-308.

13. Hu W, Lucchinetti CF. The pathological spectrum of CNS inflammatory demyelinating diseases. Semin Immunopathol 2009;31:439-453.

14. Enzinger C, Strasser-Fuchs S, Ropele S, et al. Tumefactive demyelinating lesions: conventional and advanced magnetic resonance imaging. Mult Scler 2005;11:135-139.

15. Malhotra HS, Jain KK, Agarwal A, et al. Characterization of tumefactive demyelinating lesions using MR imaging and invivo proton MR spectroscopy. Mult Scler 2009;15:193-203.

16. Cianfoni A, Niku S, Imbesi SG. Metabolite findings in tumefactive demyelinating lesions utilizing short echo time proton magnetic resonance spectroscopy. AJNR Am J Neuroradiol 2007;28:272-277.

17. Ikeda K, Ito H, Hidaka T, et al. Repeated non-enhancing tumefactive lesions in a patient with a neuromyelitis optica spectrum disorder. Intern Med 2011;50:1061-1064.

18. Saiki S, Ueno Y, Moritani T, et al. Extensive hemispheric lesions with radiological evidence of blood-brain barrier integrity in a patient with neuromyelitis optica. J Neurol Sci 2009;284:217-219.

19. Park KY, Ahn JY, Cho JH, Choi YC, Lee KS. Neuromyelitis optica with brainstem lesion mistaken for brainstem glioma. Case report. J Neurosurg 2007;107:251-254.

20. Newey CR, Bermel RA. Fulminant cerebral demyelination in neuromyelitis optica. Neurology 2011;77:193.

21. Filippini G, Brusaferri F, Sibley WA, et al. Corticosteroids or $\mathrm{ACTH}$ for acute exacerbations in multiple sclerosis. Cochrane Database Syst Rev 2000:CD001331.

22. Wiendl H, Toyka KV, Rieckmann P, et al. Basic and escalating immunomodulatory treatments in multiple sclerosis: current therapeutic recommendations. J Neurol 2008;255:1449-1463.

23. Cortese I, Chaudhry V, So YT, et al. Evidence-based guideline update: Plasmapheresis in neurologic disorders: report of the Therapeutics and Technology Assessment Subcommittee of the American Academy of Neurology. Neurology 2011;76:294-300.

24. Elovaara I, Apostolski S, van Doorn P, et al. EFNS guidelines for the use of intravenous immunoglobulin in treatment of neurological diseases: EFNS task force on the use of intravenous immunoglobulin in treatment of neurological diseases. Eur J Neurol 2008;15:893-908. 
25. Gonzalez Sanchez JJ, Nora JE, de Notaris M, et al. A case of malignant monophasic multiple sclerosis (Marburg's disease type) successfully treated with decompressive hemicraniectomy. J Neurol Neurosurg Psychiatry 2010;81:1056-7.

26. Cabre $\mathrm{P}$, Heinzlef $\mathrm{O}$, Merle $\mathrm{H}$, et al. MS and neuromyelitis optica in Martinique (French West Indies). Neurology 2001;56:507-514.

27. Cabrera-Gomez JA, Kurtzke JF, Gonzalez-Quevedo A, LaraRodriguez R. An epidemiological study of neuromyelitis optica in Cuba. J Neurol 2009;256:35-44.

28. Bizzoco E, Lolli F, Repice AM, et al. Prevalence of neuromyelitis optica spectrum disorder and phenotype distribution. J Neurol 2009;256:1891-1898.

29. Asgari N, Lillevang ST, Skejoe HP, et al. A population-based study of neuromyelitis optica in Caucasians. Neurology 2011;76:1589-1595.

30. Collongues N, Marignier R, Zephir H, et al. Neuromyelitis optica in France: a multicenter study of 125 patients. Neurology 2010;74:736-742.

31. Wingerchuk DM. Neuromyelitis optica: effect of gender. J Neurol Sci 2009;286:18-23.

32. Cree BAC, Khan O, Bourdette D, et al. Clinical characteristics of African Americans vs Caucasian Americans with multiple sclerosis. Neurology 2004;63:2039-2045.

33. Jarius S, Wildemann B. AQP4 antibodies in neuromyelitis optica: diagnostic and pathogenetic relevance. Nat Rev Neurol 2010;6:383-392.

34. Saikali P, Cayrol R, Vincent T. Anti-aquaporin-4 auto-antibodies orchestrate the pathogenesis in neuromyelitis optica. Autoimmun Rev 2009;9:132-135.

35. Cayrol R, Saikali P, Vincent T. Effector functions of antiaquaporin-4 autoantibodies in neuromyelitis optica. Ann N Y Acad Sci 2009; 1173:478-486.

36. Takano R, Misu T, Takahashi T, et al. Astrocytic damage is far more severe than demyelination in NMO: a clinical CSF biomarker study. Neurology 2010;75:208-216.

37. Cabre P, Gonzalez-Quevedo A, Bonnan M, et al. Relapsing neuromyelitis optica: long term history and clinical predictors of death. J Neurol Neurosurg Psychiatry 2009;80:1162-1164.

38. Wingerchuk DM, Lennon VA, Lucchinetti CF, Pittock SJ, Weinshenker BG. The spectrum of neuromyelitis optica. Lancet Neurol 2007;6:805815.

39. Cassinotto C, Deramond H, Olindo S, et al. MRI of the spinal cord in neuromyelitis optica and recurrent longitudinal extensive myelitis. J Neuroradiol 2009;36:199-205.

40. Pittock SJ, Weinshenker BG, Wijdicks EF. Mechanical ventilation and tracheostomy in multiple sclerosis. J Neurol Neurosurg Psychiatry 2004;75:1331-1333.

41. Wingerchuk DM, Hogancamp WF, O'Brien PC, Weinshenker BG. The clinical course of neuromyelitis optica (Devic's syndrome). Neurology 1999;53:1107-1114.

42. Wingerchuk DM, Weinshenker BG. Neuromyelitis optica: clinical predictors of a relapsing course and survival. Neurology 2003;60:848-853.

43. Win17gerchuk DM, Lennon VA, Pittock SJ, Lucchinetti CF, Weinshenker BG. Revised diagnostic criteria for neuromyelitis optica. Neurology 2006;66:1485-1489.

44. McKeon A, Fryer JP, Apiwattanakul M, et al. Diagnosis of neuromyelitis spectrum disorders: comparative sensitivities and specificities of immunohistochemical and immunoprecipitation assays. Arch Neurol 2009;66:1134-1138.

45. Sellner J, Boggild M, Clanet M, et al. EFNS guidelines on diagnosis and management of neuromyelitis optica. Eur J Neurol 2010;17:1019-1032.

46. Magana SM, Keegan BM, Weinshenker BG, et al. Beneficial plasma exchange response in central nervous system inflammatory demyelination. Arch Neurol 2011;68:870-878.
47. Carroll WM, Fujihara K. Neuromyelitis optica. Curr Treat Options Neurol;12:244-255.

48. Bedi GS, Brown AD, Delgado SR, et al. Impact of rituximab on relapse rate and disability in neuromyelitis optica. Mult Scler 2011;17:1225-1230.

49. Pellkofer HL, Krumbholz M, Berthele A, et al. Long-term followup of patients with neuromyelitis optica after repeated therapy with rituximab. Neurology 2011;76:1310-1315.

50. Kim SH, Kim W, Park MS, et al. Efficacy and safety of mitoxantrone in patients with highly relapsing neuromyelitis optica. Arch Neurol 2011;68:473-479.

51. Jacob A, Matiello M, Weinshenker BG, et al. Treatment of neuromyelitis optica with mycophenolate mofetil: retrospective analysis of 24 patients. Arch Neurol 2009;66:1128-1133.

52. Costanzi C, Matiello M, Lucchinetti CF, et al. Azathioprine: Tolerability, efficacy, and predictors of benefit in neuromyelitis optica. Neurology 2011;77:659-666.

53. Leake JA, Albani S, Kao AS, et al. Acute disseminated encephalomyelitis in childhood: epidemiologic, clinical and laboratory features. Pediatr Infect Dis J 2004;23:756-764.

54. Panicker JN, Nagaraja D, Kovoor JM, Subbakrishna DK. Descriptive study of acute disseminated encephalomyelitis and evaluation of functional outcome predictors. J Postgrad Med 2010;56:12-16.

55. Sonneville R, Demeret S, Klein I, et al. Acute disseminated encephalomyelitisin the intensive care unit:clinical features and outcome of 20 adults. Intensive Care Med 2008;34:528-532.

56. Menge T, Hemmer B, Nessler S, et al. Acute disseminated encephalomyelitis: an update. Arch Neurol 2005;62:1673-1680.

57. Rossi A. Imaging of acute disseminated encephalomyelitis. Neuroimaging Clin N Am 2008;18:149-161.

58. Balasubramanya KS, Kovoor JM, Jayakumar PN, et al. Diffusion-weighted imaging and proton MR spectroscopy in the characterization of acute disseminated encephalomyelitis. Neuroradiology 2007;49:177-183.

59. Franciotta D, Columba-Cabezas S, Andreoni L, et al. Oligoclonal IgG band patterns in inflammatory demyelinating human and mouse diseases. J Neuroimmunol 2008;200:125-128.

60. Abou Zeid NE, Burns JD, Wijdicks EF, Giannini C, Keegan BM. Atypical acute hemorrhagic leukoencephalitis (Hurst's disease) presenting with focal hemorrhagic brainstem lesion. Neurocrit Care 2011;12:95-97.

61. Pinto PS, Taipa R, Moreira B, Correia C, Melo-Pires M. Acute hemorrhagic leukoencephalitis with severe brainstem and spinal cord involvement: MRI features with neuropathological confirmation. J Magn Reson Imaging 2011;33:957-91.

62. Davies NW, Sharief MK, Howard RS. Infection-associated encephalopathies: their investigation, diagnosis, and treatment. J Neurol 2006;253:833-845.

63. Probstel AK, Dornmair K, Bittner R, et al. Antibodies to MOG are transient in childhood acute disseminated encephalomyelitis. Neurology 2011;77:580-588.

64. Brilot F, Dale RC, Selter RC, et al. Antibodies to native myelin oligodendrocyte glycoprotein in children with inflammatory demyelinating central nervous system disease. Ann Neurol 2009;66:833-942.

65. Selter RC, Brilot F, Grummel V, et al. Antibody responses to EBV and native MOG in pediatric inflammatory demyelinating CNS diseases. Neurology 2010;74:1711-1715.

66. Di Pauli F, Mader S, Rostasy K, et al. Temporal dynamics of antiMOG antibodies in CNS demyelinating diseases. Clin Immunol 2011;138:247-254.

67. Zaguri R, Shelef I, Ifergan G, Almog Y. Fatal acute disseminated encephalomyelitis associated with cytomegalovirus infection. BMJ Case Rep 2009. doi:10.1136/bcr.07.2008.0443.

68. Hofer M, Weber A, Haffner K, et al. Acute hemorrhagic leukoencephalitis (Hurst's disease) linked to Epstein-Barr virus infection. Acta Neuropathol 2005;109:226-230. 
69. Kumar RS, Kuruvilla A. Teaching Neuroimages: acute hemorrhagic leukoencephalitis after mumps. Neurology 2009;73:e98.

70. Kabakus N, Gurgoze MK, Yildirim H, Godekmerdan A, Aydin $\mathrm{M}$. Acute hemorrhagic leukoencephalitis manifesting as intracerebral hemorrhage associated with herpes simplex virus type I. J Trop Pediatr 2005;51:245-249.

71. Fugate JE, Lam EM, Rabinstein AA, Wijdicks EF. Acute hemorrhagic leukoencephalitis and hypoxic brain injury associated with H1N1 influenza. Arch Neurol 2010;67:756-758.

72. Ahmed AI, Eynon CA, Kinton L, Nicoll JA, Belli A. Decompressive craniectomy for acute disseminated encephalomyelitis. Neurocrit Care 2010;13:393-395.

73. Dombrowski KE, Mehta AI, Turner DA, McDonagh DL. Lifesaving hemicraniectomy for fulminant acute disseminated encephalomyelitis. Br J Neurosurg 2011;25:249-252.

74. Payne ET, Rutka JT, Ho TK, Halliday WC, Banwell BL. Treatment leading to dramatic recovery in acute hemorrhagic leukoencephalitis. J Child Neurol 2007;22:109-113.

75. Takata T, Hirakawa M, Sakurai M, Kanazawa I. Fulminant form of acute disseminated encephalomyelitis: successful treatment with hypothermia. J Neurol Sci 1999;165:94-97.

76. Schwarz S, Mohr A, Knauth M, Wildemann B, Storch-Hagenlocher B. Acute disseminated encephalomyelitis: a follow-up study of 40 adult patients. Neurology 2001;56:1313-1318.

77. Bhat A, Naguwa S, Cheema G, Gershwin ME. The epidemiology of transverse myelitis. Autoimmun Rev 2010;9:A395-A399.

78. de Seze J, Lanctin C, Lebrun C, et al. Idiopathic acute transverse myelitis: application of the recent diagnostic criteria. Neurology 2005;65:1950-1953.

79. Young J, Quinn S, Hurrell M, Taylor B. Clinically isolated acute transverse myelitis: prognostic features and incidence. Mult Scler 2009;15:1295-1302.

80. Bruna J, Martinez-Yelamos S, Martinez-Yelamos A, Rubio F, Arbizu T. Idiopathic acute transverse myelitis: a clinical study and prognostic markers in 45 cases. Mult Scler 2006;12:169-173.

81. D'Cruz DP, Mellor-Pita S, Joven B, et al. Transverse myelitis as the first manifestation of systemic lupus erythematosus or lupuslike disease: good functional outcome and relevance of antiphospholipid antibodies. J Rheumatol 2004;31:280-285.

82. Chen HC, Lai JH, Juan CJ, et al. Longitudinal myelitis as an initial manifestation of systemic lupus erythematosus. Am J Med Sci 2004;327:105-108.

83. Dolhun R, Sriram S. Neurosarcoidosis presenting as longitudinally extensive transverse myelitis. Journal of Clinical Neuroscience 2009;16:595-597.

84. Kerr DA, Ayetey H. Immunopathogenesis of acute transverse myelitis. Curr Opin Neurol 2002;15:339-347.

85. Weinshenker BG, O'Brien PC, Petterson TM, et al. A randomized trial of plasma exchange in acute central nervous system inflammatory demyelinating disease. Ann Neurol 1999;46:878-886.

86. Greenberg BM, Thomas KP, Krishnan C, et al. Idiopathic transverse myelitis: corticosteroids, plasma exchange, or cyclophosphamide. Neurology 2007;68:1614-1617.

87. Hughes RA, Cornblath DR. Guillain-Barre syndrome. Lancet 2005;366:1653-1666.

88. Chio A, Cocito D, Leone M, et al. Guillain-Barre syndrome: a prospective, population-based incidence and outcome survey. Neurology 2003;60:1146-1150.

89. Leis AA, Stokic DS. Neuromuscular Manifestations of Human West Nile Virus Infection. Curr Treat Options Neurol 2005;7:1522.

90. Cabrera Serrano M, Rabinstein AA. Causes and outcomes of acute neuromuscular respiratory failure. Arch Neurol 2010;67:1089-1094.

91. Patel MB, Goyal SK, Punnam SR, et al. Guillain-Barre Syndrome with asystole requiring permanent pacemaker: a case report. J Med Case Reports 2009;3:5.
92. Minahan RE Jr., Bhardwaj A, Traill TA, Hanley DF. Stimulusevoked sinus arrest in severe Guillain-Barre syndrome: a case report. Neurology 1996;47:1239-1242.

93. Bouget J, Chevret S, Chastang C, Raphael JC. Plasma exchange morbidity in Guillain-Barre syndrome: results from the French prospective, randomized, multicenter study. The French Cooperative Group. Crit Care Med 1993;21:651-658.

94. Maytal J, Eviatar L, Brunson SC, Gootman N. Use of demand pacemaker in children with Guillain-Barre syndrome and cardiac arrhythmias. Pediatr Neurol 1989;5:303-305.

95. Narayan D, Huang MT, Mathew PK. Bradycardia and asystole requiring permanent pacemaker in Guillain-Barre syndrome. Am Heart J 1984;108:426-428.

96. Emmons PR, Blume WT, DuShane JW. Cardiac monitoring and demand pacemaker in Guillain-Barre syndrome. Arch Neurol 1975;32:59-61.

97. Raphael JC, Chevret S, Hughes RA, Annane D. Plasma exchange for Guillain-Barre syndrome. Cochrane Database Syst Rev 2001: CD001798.

98. Hughes RA, Swan AV, van Doorn PA. Intravenous immunoglobulin for Guillain-Barre syndrome. Cochrane Database Syst Rev 2010:CD002063.

99. Hughes RA, Swan AV, van Doorn PA. Corticosteroids for GuillainBarré syndrome. Cochrane Database Syst Rev 2010:CD001446.

100. Appropriate number of plasma exchanges in Guillain-Barré syndrome. The French Cooperative Group on Plasma Exchange in Guillain-Barre Syndrome. Ann Neurol 1997;41:298-306.

101. Souayah N, Nasar A, Suri MF, Qureshi AI. National trends in hospital outcomes among patients with Guillain-Barre syndrome requiring mechanical ventilation. J Clin Neuromuscul Dis 2008; 10:24-28.

102. Alshekhlee A, Hussain Z, Sultan B, Katirji B. Immunotherapy for Guillain-Barre syndrome in the US hospitals. J Clin Neuromuscul Dis 2008;10:4-10.

103. Rees JH, Thompson RD, Smeeton NC, Hughes RA. Epidemiological study of Guillain-Barré syndrome in south east England. J Neurol Neurosurg Psychiatry 1998;64:74-77.

104. Dhar R, Stitt L, Hahn AF. The morbidity and outcome of patients with Guillain-Barre syndrome admitted to the intensive care unit. J Neurol Sci 2008;264:121-128.

105. Kohrmann M, Huttner HB, Nowe T, Schellinger PD, Schwab S. Mechanical ventilation in Guillain-Barre syndrome: does age influence functional outcome? Eur Neurol 2009;61:358-363.

106. Alshekhlee A, Hussain Z, Sultan B, Katirji B. Guillain-Barre syndrome: incidence and mortality rates in US hospitals. Neurology 2008;70:1608-1613.

107. Ito M, Kuwabara S, Odaka M, et al. Bickerstaff's brainstem encephalitis and Fisher syndrome form a continuous spectrum: clinical analysis of 581 cases. J Neurol 2008;255:674-682.

108. Odaka M, Yuki N, Yamada M, et al. Bickerstaff's brainstem encephalitis: clinical features of 62 cases and a subgroup associated with Guillain-Barré syndrome. Brain 2003;126:2279-2290.

109. Overell JR, Willison HJ. Recent developments in Miller Fisher syndrome and related disorders. Curr Opin Neurol 2005;18:562-586.

110. Odaka M, Yuki N, Hirata K. Patients with chronic inflammatory demyelinating polyneuropathy initially diagnosed as GuillainBarre syndrome. J Neurol 2003;250:913-916.

111. Overell JR, Hsieh ST, Odaka M, Yuki N, Willison HJ. Treatment for Fisher syndrome, Bickerstaff's brainstem encephalitis and related disorders. Cochrane Database Syst Rev 2007:CD004761.

112. van Doorn PA, Ruts L, Jacobs BC. Clinical features, pathogenesis, and treatment of Guillain-Barre syndrome. Lancet Neurol 2008;7:939-950.

113. Salvarani C, Brown RD, Jr., Calamia KT, et al. Primary central nervous system vasculitis: analysis of 101 patients. Ann Neurol 2007;62:442-451. 
114. Hajj-Ali RA, Singhal AB, Benseler S, Molloy E, Calabrese LH. Primary angiitis of the CNS. Lancet Neurol 2011;10:561-572.

115. Calabrese LH, Dodick DW, Schwedt TJ, Singhal AB. Narrative review: reversible cerebral vasoconstriction syndromes. Ann Intern Med 2007;146:34-44.

116. Ducros A, Boukobza M, Porcher R, et al. The clinical and radiological spectrum of reversible cerebral vasoconstriction syndrome. A prospective series of 67 patients. Brain 2007;130:3091-3101.

117. Cupps TR, Moore PM, Fauci AS. Isolated angiitis of the central nervous system. Prospective diagnostic and therapeutic experience. Am J Med 1983;74:97-105.

118. Miller DV, Salvarani C, Hunder GG, et al. Biopsy findings in primary angiitis of the central nervous system. Am J Surg Pathol 2009;33:35-43.

119. Molloy ES, Hajj-Ali RA. Primary angiitis of the central nervous system. Curr Treat Options Neurol 2007;9:169-175.

120. Salvarani C, Brown RD, Jr., Calamia KT, et al. Efficacy of tumor necrosis factor alpha blockade in primary central nervous system vasculitis resistant to immunosuppressive treatment. Arthritis Rheum 2008;59:291-296.

121. Sen ES, Leone V, Abinun M, et al. Treatment of primary angiitis of the central nervous system in childhood with mycophenolate mofetil. Rheumatology (Oxford) 2010;49:806-811.

122. Chenevier F, Renoux C, Marignier R, et al. Primary angiitis of the central nervous system: response to mycophenolate mofetil. J Neurol Neurosurg Psychiatry 2009;80:1159-1161.

123. Scolding NJ, Joseph F, Kirby PA, et al. Abeta-related angiitis: primary angiitis of the central nervous system associated with cerebral amyloid angiopathy. Brain 2005;128:500-515.

124. Rigby H, Easton A, Bhan V. Amyloid beta-related Angiitis of the Central Nervous System: Report of 3 Cases. Can J Neurol Sci 2011;38:626-630.

125. Salloway S, Sperling R, Gilman S, et al. A phase 2 multiple ascending dose trial of bapineuzumab in mild to moderate Alzheimer disease. Neurology 2009;73:2061-2070.

126. Hermann DM, Keyvani K, van de Nes J, et al. Brain-reactive \{beta\}-amyloid antibodies in primary CNS angiitis with cerebral amyloid angiopathy. Neurology 2011;77:503-505.

127. DiFrancesco JC, Brioschi M, Brighina L, et al. Anti-A beta autoantibodies in the CSF of a patient with CAA-related inflammation: A case report. Neurology 2011;76:842-844.

128. Kinnecom C, Lev MH, Wendell L, et al. Course of cerebral amyloid angiopathy-related inflammation. Neurology 2007;68:14111416.

129. Chung KK, Anderson NE, Hutchinson D, Synek B, Barber PA. Cerebral amyloid angiopathy related inflammation: three case reports and a review. J Neurol Neurosurg Psychiatry 2011;82:20-26.

130. Salvarani C, Brown RD, Jr., Calamia KT, et al. Primary central nervous system vasculitis: comparison of patients with and without cerebral amyloid angiopathy. Rheumatology (Oxford) 2008;47:1671-1677.

131. Kloppenborg RP, Richard E, Sprengers ME, et al. Steroid responsive encephalopathy in cerebral amyloid angiopathy: a case report and review of evidence for immunosuppressive treatment. J Neuroinflammation 2010;7:18.

132. Daniels R, Geurts JJ, Bot JC, Schonewille WJ, van Oosten BW. Steroid-responsive edema in CAA-related inflammation. J Neurol 2009;256:285-286.

133. Gonzalez-Gay MA, Garcia-Porrua C. Epidemiology of the vasculitides. Rheum Dis Clin North Am 2001;27:729-749.

134. Gonzalez-Gay MA, Vazquez-Rodriguez TR, Gomez-Acebo I, et al. Strokes at time of disease diagnosis in a series of 287 patients with biopsy-proven giant cell arteritis. Medicine (Baltimore) 2009;88:227-235

135. Solans-Laque R, Bosch-Gil JA, Molina-Catenario CA, et al. Stroke and multi-infarct dementia as presenting symptoms of giant cell arteritis: report of 7 cases and review of the literature. Medicine (Baltimore) 2008;87:335-344.

136. Phillip R, Luqmani R. Mortality in systemic vasculitis: a systematic review. Clin Exp Rheumatol 2008;26:S94-S104.

137. Lu-Emerson C, Walker M, Huber BR, et al. Lethal giant cell arteritis with multiple ischemic strokes despite aggressive immunosuppressive therapy. J Neurol Sci 2010;295:120-124.

138. Jennette JC. Nomenclature and classification of vasculitis: lessons learned from granulomatosis with polyangiitis (Wegener's granulomatosis). Clin Exp Immunol 2011;164(suppl 1):7-10.

139. Seo P, Stone JH. The antineutrophil cytoplasmic antibodyassociated vasculitides. Am J Med 2004;117:39-50.

140. Bosch X, Guilabert A, Font J. Antineutrophil cytoplasmic antibodies. Lancet 2006;368:404-418.

141. Watts RA, Al-Taiar A, Scott DG, Macgregor AJ. Prevalence and incidence of Wegener's granulomatosis in the UK general practice research database. Arthritis Rheum 2009;61:1412-1416.

142. Mohammad AJ, Jacobsson LT, Mahr AD, Sturfelt G, Segelmark M. Prevalence of Wegener's granulomatosis, microscopic polyangiitis, polyarteritis nodosa and Churg-Strauss syndrome within a defined population in southern Sweden. Rheumatology (Oxford) 2007;46:1329-1337.

143. Nishino H, Rubino FA, DeRemee RA, Swanson JW, Parisi JE. Neurological involvement in Wegener's granulomatosis: an analysis of 324 consecutive patients at the Mayo Clinic. Ann Neurol 1993;33:4-9.

144. Holle JU, Gross WL. Neurological involvement in Wegener's granulomatosis. Curr Opin Rheumatol 2011;23:7-11.

145. Leavitt RY, Fauci AS, Bloch DA, et al. The American College of Rheumatology 1990 criteria for the classification of Wegener's granulomatosis. Arthritis Rheum 1990;33:1101-1107.

146. Chan M, Luqmani R. Pharmacotherapy of vasculitis. Expert Opin Pharmacother 2009;10:1273-1289.

147. Stone JH, Merkel PA, Spiera R, et al. Rituximab versus cyclophosphamide for ANCA-associated vasculitis. N Engl J Med 2010;363:221-232.

148. Chen M, Kallenberg CG. ANCA-associated vasculitidesadvances in pathogenesis and treatment. Nat Rev Rheumatol 2010;6:653-664.

149. Fortin PM, Tejani AM, Bassett K, Musini VM. Intravenous immunoglobulin as adjuvant therapy for Wegener's granulomatosis. Cochrane Database Syst Rev 2009:CD007057.

150. Pagnoux C, Mahr A, Hamidou MA, et al. Azathioprine or methotrexate maintenance for ANCA-associated vasculitis. N Engl J Med 2008;359:2790-2803.

151. Mukhtyar C, Flossmann O, Hellmich B, et al. Outcomes from studies of antineutrophil cytoplasm antibody associated vasculitis: a systematic review by the European League Against Rheumatism systemic vasculitis task force. Ann Rheum Dis 2008;67:1004-1010.

152. Bosch X, Guilabert A, Espinosa G, Mirapeix E. Immunotherapy for antineutrophil cytoplasmic antibody-associated vasculitis: challenging the therapeutic status quo? Trends Immunol 2008;29:280-289.

153. Zhang W, Zhou G, Shi Q, et al. Clinical analysis of nervous system involvement in ANCA-associated systemic vasculitides. Clin Exp Rheumatol 2009;27:S65-S69.

154. Ozkul A, Tataroglu C, Kiylioglu N, Akyol A. Microscopic polyangiitis presenting with medullary infarct. J Neurol Sci 2011;300:173-175.

155. Tang CW, Wang PN, Lin KP, et al. Microscopic polyangiitis presenting with capsular warning syndrome and subsequent stroke. J Neurol Sci 2009;277:174-175.

156. Isoda K, Nuri K, Shoda T, et al. Microscopic polyangiitis complicated with cerebral infarction and hemorrhage: a case report and review of literature. Nihon Rinsho Meneki Gakkai Kaishi 2010;33:111-115. 
157. Ku BD, Shin HY. Multiple bilateral non-hemorrhagic cerebral infarctions associated with microscopic polyangiitis. Clin Neurol Neurosurg 2009;111:904-906.

158. Ito Y, Suzuki K, Yamazaki T, et al. ANCA-associated vasculitis (AAV) causing bilateral cerebral infarction and subsequent intracerebral hemorrhage without renal and respiratory dysfunction. J Neurol Sci 2006;240:99-101.

159. Sable-Fourtassou R, Cohen P, Mahr A, et al. Antineutrophil cytoplasmic antibodies and the Churg-Strauss syndrome. Ann Intern Med 2005; 143:632-638.

160. Guillevin L, Cohen P, Gayraud M, et al. Churg-Strauss syndrome. Clinical study and long-term follow-up of 96 patients. Medicine (Baltimore) 1999;78:26-37.

161. Wolf J, Bergner R, Mutallib S, Buggle F, Grau AJ. Neurologic complications of Churg-Strauss syndrome-a prospective monocentric study. Eur J Neurol 2010;17:582-588.

162. Sehgal M, Swanson JW, DeRemee RA, Colby TV. Neurologic manifestations of Churg-Strauss syndrome. Mayo Clin Proc 1995; 70:337-341

163. Saech J, Owczarczyk K, Rosgen S, et al. Successful use of rituximab in a patient with Churg-Strauss syndrome and refractory central nervous system involvement. Ann Rheum Dis 2010;69:1254-1255.

164. Cartin-Ceba R, Keogh KA, Specks U, Sethi S, Fervenza FC. Rituximab for the treatment of Churg-Strauss syndrome with renal involvement. Nephrol Dial Transplant 2011;26:2865-2671.

165. Yurdakul S, Yazici H. Behcet's syndrome. Best Pract Res Clin Rheumatol 2008;22:793-809.

166. Al-Araji A, Kidd DP. Neuro-Behcet's disease: epidemiology, clinical characteristics, and management. Lancet Neurol 2009;8:192204.

167. Davatchi F, Shahram F, Chams-Davatchi C, et al. Behcet's disease: from East to West. Clin Rheumatol 2010;29:823-833.

168. Criteria for diagnosis of Behcet's disease. International Study Group for Behcet's Disease. Lancet 1990;335:1078-1080.

169. Akman-Demir G, Bahar S, Coban O, Tasci B, Serdaroglu P. Cranial MRI in Behcet's disease: 134 examinations of 98 patients. Neuroradiology 2003;45:851-859.

170. Yesilot N, Mutlu M, Gungor O, et al. Clinical characteristics and course of spinal cord involvement in Behcet's disease. Eur J Neurol 2007;14:729-737.

171. Akman-Demir G, Serdaroglu P, Tasci B. Clinical patterns of neurological involvement in Behcet's disease: evaluation of 200 patients. The Neuro-Behcet Study Group. Brain 1999;122 (pt 11):2171-2182.

172. Siva A, Saip S. The spectrum of nervous system involvement in Behcet's syndrome and its differential diagnosis. J Neurol 2009;256:513-529.

173. Aguiar de Sousa D, Mestre T, Ferro JM. Cerebral venous thrombosis in Behcet's disease: a systematic review. J Neurol 2011;258:719727.

174. Yamada Y, Sugita S, Tanaka H, et al. Comparison of infliximab versus ciclosporin during the initial 6-month treatment period in Behcet disease. Br J Ophthalmol 2010;94:284-288.

175. Giardina A, Ferrante A, Ciccia F, et al. One year study of efficacy and safety of infliximab in the treatment of patients with ocular and neurological Behcet's disease refractory to standard immunosuppressive drugs. Rheumatol Int 2011;31:33-37.

176. Stam J, De Bruijn SF, DeVeber G. Anticoagulation for cerebral sinus thrombosis. Cochrane Database Syst Rev 2002:CD002005.

177. Saadoun D, Wechsler B, Desseaux K, et al. Mortality in Behcet's disease. Arthritis Rheum 2010;62:2806-2812.

178. Rybicki BA, Iannuzzi MC. Epidemiology of sarcoidosis: recent advances and future prospects. Semin Respir Crit Care Med 2007;28:22-35.

179. Pawate S, Moses H, Sriram S. Presentations and outcomes of neurosarcoidosis: a study of 54 cases. QJM 2009;102:449-460.
180. Joseph FG, Scolding NJ. Neurosarcoidosis: a study of 30 new cases. J Neurol Neurosurg Psychiatry 2009;80:297-304.

181. Hoitsma E, Drent M, Sharma OP. A pragmatic approach to diagnosing and treating neurosarcoidosis in the 21 st century. Curr Opin Pulm Med 2010;16:472-479.

182. Terushkin V, Stern BJ, Judson MA, et al. Neurosarcoidosis: presentations and management. Neurologist 2010;16:2-15.

183. Murialdo G, Tamagno G. Endocrine aspects of neurosarcoidosis. J Endocrinol Invest 2002;25:650-662.

184. Bradley DA, Lower EE, Baughman RP. Diagnosis and management of spinal cord sarcoidosis. Sarcoidosis Vasc Diffuse Lung Dis 2006;23:58-65.

185. Fahoum F, Drory VE, Issakov J, Neufeld MY. Neurosarcoidosis presenting as Guillain-Barre-like syndrome. A case report and review of the literature. J Clin Neuromuscul Dis 2009;11:35-43.

186. Berhouma M, Abderrazek K, Krichen W, Jemel H. Apropos of an unusual and menacing presentation of neurosarcoidosis: the space-occupying trapped temporal horn. Clin Neurol Neurosurg 2009;111:196-199.

187. Westhout FD, Linskey ME. Obstructive hydrocephalus and progressive psychosis: rare presentations of neurosarcoidosis. Surg Neurol 2008;69:288-292.

188. Dubrey SW, Falk RH. Diagnosis and management of cardiac sarcoidosis. Prog Cardiovasc Dis;52:336-346.

189. Lury KM, Smith JK, Matheus MG, Castillo M. Neurosarcoidosisreview of imaging findings. Semin Roentgenol 2004;39:495-504.

190. Tahmoush AJ, Amir MS, Connor WW, et al. CSF-ACE activity in probable CNS neurosarcoidosis. Sarcoidosis Vasc Diffuse Lung Dis 2002;19:191-197.

191. Moravan M, Segal BM. Treatment of CNS sarcoidosis with infliximab and mycophenolate mofetil. Neurology 2009;72:337-340.

192. Carter JD, Valeriano J, Vasey FB, Bognar B. Refractory neurosarcoidosis: a dramatic response to infliximab. Am J Med 2004;117:277-279.

193. Pettersen JA, Zochodne DW, Bell RB, Martin L, Hill MD. Refractory neurosarcoidosis responding to infliximab. Neurology 2002;59:1660-1661.

194. Bomprezzi R, Pati S, Chansakul C, Vollmer T. A case of neurosarcoidosis successfully treated with rituximab. Neurology 2010;75:568-570.

195. Sharma OP. Effectiveness of chloroquine and hydroxychloroquine in treating selected patients with sarcoidosis with neurological involvement. Arch Neurol 1998;55:1248-1254.

196. Swigris JJ, Olson AL, Huie TJ, et al. Sarcoidosis-related mortality in the United States from 1988 to 2007. Am J Respir Crit Care Med 2011;183:1524-1530.

197. Hatron PY, Tillie-Leblond I, Launay D, et al. Pulmonary manifestations of Sjogren's syndrome. Presse Med;40:e49-e64.

198. Gono T, Kawaguchi Y, Katsumata Y, et al. Clinical manifestations of neurological involvement in primary Sjogren's syndrome. Clin Rheumatol 2011;30:485-490.

199. Mavragani CP, Moutsopoulos HM. The geoepidemiology of Sjogren's syndrome. Autoimmun Rev 2010;9:A305-A310.

200. Shapira Y, Agmon-Levin N, Shoenfeld Y. Geoepidemiology of autoimmune rheumatic diseases. Nat Rev Rheumatol 2010;6:468476.

201. Massara A, Bonazza S, Castellino G, et al. Central nervous system involvement in Sjogren's syndrome: unusual, but not unremarkable-clinical, serological characteristics and outcomes in a large cohort of Italian patients. Rheumatology (Oxford) 2010;49:1540-1549.

202. Niemela RK, Hakala M. Primary Sjogren's syndrome with severe central nervous system disease. Semin Arthritis Rheum 1999;29:4-13.

203. Rogers SJ, Williams CS, Roman GC. Myelopathy in Sjogren's syndrome: role of nonsteroidal immunosuppressants. Drugs 2004;64:123-132. 
204. Delalande S, de Seze J, Fauchais AL, et al. Neurologic manifestations in primary Sjogren syndrome: a study of 82 patients. Medicine (Baltimore) 2004;83:280-291.

205. Sanahuja J, Ordonez-Palau S, Begue R, Brieva L, Boquet D. Primary Sjogren Syndrome with tumefactive central nervous system involvement. AJNR Am J Neuroradiol 2008;29:18781879.

206. Chang Y, Horoupian DS, Lane B, et al. Inflammatory pseudotumor of the choroid plexus in Sjogren's disease. Neurosurgery 1991;29:287-290.

207. Pericot I, Brieva L, Tintore M, et al. Myelopathy in seronegative Sjogren syndrome and/or primary progressive multiple sclerosis. Mult Scler 2003;9:256-259.

208. Michel L, Toulgoat F, Desal H, et al. Atypical neurologic complications in patients with primary Sjogren's syndrome: report of 4 cases. Semin Arthritis Rheum 2010;40:338-342.

209. Segal B, Carpenter A, Walk D. Involvement of nervous system pathways in primary Sjogren's syndrome. Rheum Dis Clin North Am 2008;34:885-906.

210. Vitali C, Bombardieri S, Jonsson R, et al. Classification criteria for Sjogren's syndrome: a revised version of the European criteria proposed by the American-European Consensus Group. Ann Rheum Dis 2002;61:554-558.

211. Mavragani CP, Moutsopoulos NM, Moutsopoulos HM. The management of Sjogren's syndrome. Nat Clin Pract Rheumatol 2006;2:252-261.

212. Ramos-Casals M, Garcia-Hernandez FJ, de Ramon E, et al. Offlabel use of rituximab in 196 patients with severe, refractory systemic autoimmune diseases. Clin Exp Rheumatol 2010;28:468476.

213. Chai J, Logigian EL. Neurological manifestations of primary Sjogren's syndrome. Curr Opin Neurol 2010;23:509-513.

214. Weng MY, Huang YT, Liu MF, Lu TH. Incidence and mortality of treated primary Sjogren's syndrome in Taiwan: a populationbased study. J Rheumatol 2011;38:706-708.

215. Zhang W, Feng S, Yan S, et al. Incidence of malignancy in primary Sjogren's syndrome in a Chinese cohort. Rheumatology (Oxford) 2010;49:571-577.

216. Voulgarelis M, Dafni UG, Isenberg DA, Moutsopoulos HM. Malignant lymphoma in primary Sjogren's syndrome: a multicenter, retrospective, clinical study by the European Concerted Action on Sjogren's Syndrome. Arthritis Rheum 1999;42:17651772 .

217. Bertsias GK, Boumpas DT. Pathogenesis, diagnosis and management of neuropsychiatric SLE manifestations. Nat Rev Rheumatol 2010;6:358-367.

218. Kovacs B, Lafferty TL, Brent LH, DeHoratius RJ. Transverse myelopathy in systemic lupus erythematosus: an analysis of 14 cases and review of the literature. Ann Rheum Dis 2000;59:120 124.

219. Gibson T, Myers AR. Nervous system involvement in systemic lupus erythematosus. Ann Rheum Dis 1975;35:398-406.

220. Ansari A, Larson PH, Bates HD. Vascular manifestations of systemic lupus erythematosus. Angiology 1986;37:423-432.

221. Sibbitt WL Jr., Brooks WM, Kornfeld M, et al. Magnetic resonance imaging and brain histopathology in neuropsychiatric systemic lupus erythematosus. Semin Arthritis Rheum 2010;40:32-52.

222. Bertsias GK, Ioannidis JP, Aringer M, et al. EULAR recommendations for the management of systemic lupus erythematosus with neuropsychiatric manifestations: report of a task force of the EULAR standing committee for clinical affairs. Ann Rheum Dis 2010;69:2074-2082.

223. Trevisani VF, Castro AA, Neves Neto JF, Atallah AN. Cyclophosphamide versus methylprednisolone for treating neuropsychiatric involvement in systemic lupus erythematosus. Cochrane Database Syst Rev 2006:CD002265.
224. Barile-Fabris L, Ariza-Andraca R, Olguin-Ortega L, et al. Controlled clinical trial of IV cyclophosphamide versus IV methylprednisolone in severe neurological manifestations in systemic lupus erythematosus. Ann Rheum Dis 2005;64:620-625.

225. Cervera R, Bucciarelli S, Plasin MA, et al. Catastrophic antiphospholipid syndrome (CAPS): descriptive analysis of a series of 280 patients from the "CAPS Registry". J Autoimmun 2009;32:240-245.

226. Bucciarelli S, Espinosa G, Cervera R, et al. Mortality in the catastrophic antiphospholipid syndrome: causes of death and prognostic factors in a series of 250 patients. Arthritis Rheum 2006;54:2568-2576.

227. Espinosa G, Bucciarelli S, Asherson RA, Cervera R. Morbidity and mortality in the catastrophic antiphospholipid syndrome: pathophysiology, causes of death, and prognostic factors. Semin Thromb Hemost 2008;34:290-294.

228. Pons-Estel GJ, Salerni GE, Serrano RM, et al. Therapeutic plasma exchange for the management of refractory systemic autoimmune diseases: Report of 31 cases and review of the literature. Autoimmun Rev 2011;10:679-684.

229. Espinosa G, Berman H, Cervera R. Management of refractory cases of catastrophic antiphospholipid syndrome. Autoimmun Rev 2011;10:664-668.

230. Lai M, Huijbers MG, Lancaster E, et al. Investigation of LGI1 as the antigen in limbic encephalitis previously attributed to potassium channels: a case series. Lancet Neurol 2010;9:776-785.

231. Lancaster E, Huijbers MG, Bar V, et al. Investigations of caspr2, an autoantigen of encephalitis and neuromyotonia. Ann Neurol 2011;69:303-311.

232. Bataller L, Galiano R, Garcia-Escrig M, et al. Reversible paraneoplastic limbic encephalitis associated with antibodies to the AMPA receptor. Neurology 2010;74:265-267.

233. Boronat A, Sabater L, Saiz A, Dalmau J, Graus F. GABA(B) receptor antibodies in limbic encephalitis and anti-GAD-associated neurologic disorders. Neurology 2011;76:795-800.

234. Malter MP, Helmstaedter C, Urbach H, Vincent A, Bien CG. Antibodies to glutamic acid decarboxylase define a form of limbic encephalitis. Ann Neurol 2010;67:470-478.

235. Mata S, Muscas GC, Naldi I, et al. Non-paraneoplastic limbic encephalitis associated with anti-glutamic acid decarboxylase antibodies. J Neuroimmunol 2008;199:155-159.

236. Dalmau J. Recognizing paraneoplastic limbic encephalitis. J Clin Oncol 2009;27:e230-e231.

237. Titulaer MJ, Soffietti R, Dalmau J, et al. Screening for tumours in paraneoplastic syndromes: report of an EFNS task force. Eur J Neurol 2011;18:19-27.

238. Kaymakamzade B, Kansu T, Tan E, Dericioglu N. LGI1 related limbic encephalitis and response to immunosuppressive therapy. J Neurol 2011 258:2075-2077.

239. Irani SR, Alexander S, Waters $\mathrm{P}$, et al. Antibodies to Kv1 potassium channel-complex proteins leucine-rich, glioma inactivated 1 protein and contactin-associated protein-2 in limbic encephalitis, Morvan's syndrome and acquired neuromyotonia. Brain 2010;133:2734 2748.

240. Dalmau J, Tuzun E, Wu HY, et al. Paraneoplastic anti-N-methylD-aspartate receptor encephalitis associated with ovarian teratoma. Ann Neurol 2007;61:25-36.

241. Wandinger KP, Saschenbrecker S, Stoecker W, Dalmau J. AntiNMDA-receptor encephalitis: a severe, multistage, treatable disorder presenting with psychosis. J Neuroimmunol 2010;231:86-91.

242. Tuzun E, Zhou L, Baehring JM, et al. Evidence for antibodymediated pathogenesis in anti-NMDAR encephalitis associated with ovarian teratoma. Acta Neuropathol 2009;118:737-743.

243. Dalmau J, Lancaster E, Martinez-Hernandez E, Rosenfeld MR, Balice-Gordon R. Clinical experience and laboratory investigations in patients with anti-NMDAR encephalitis. Lancet Neurol 2011;10:6374. 
244. Dalmau J. Status epilepticus due to paraneoplastic and nonparaneoplastic encephalitides. Epilepsia 2009;50(suppl 12):58-60.

245. Dalmau J, Gleichman AJ, Hughes EG, et al. Anti-NMDAreceptor encephalitis: case series and analysis of the effects of antibodies. Lancet Neurol 2008;7:1091-1098.

246. Chia PL, Tan K, Foo D. Profound Sinus Node Dysfunction in Anti-N-Methyl-D-Aspartate Receptor Limbic Encephalitis. Pacing Clin Electrophysiol 2011. doi:10.1111/j.15408159.2011.03154.x.

247. McGinley J, McCabe DJ, Fraser A, et al. Hashimoto's encephalopathy; an unusual cause of status epilepticus. Ir Med J 2000;93:118.

248. Rekand T, Vedeler C, Gramstad A, Bindoff L. Hashimoto's encephalopathy: a treatable cause of mental impairment, stroke and seizures. Eur J Neurol 2003;10:746-747.

249. Bonmann E, Prumbaum M, Stippich C, Ringleb P, Sliwka U. Hashimoto encephalopathy: rare cause of stroke in young patient. Neurologist 2009;15:342-344.

250. Gucuyener K, Serdaroglu A, Bideci A, et al. Tremor and myoclonus heralding Hashimoto's encephalopathy. J Pediatr Endocrinol Metab 2000;13:1137-1141.

251. Castillo P, Woodruff B, Caselli R, et al. Steroid-responsive encephalopathy associated with autoimmune thyroiditis. Arch Neurol 2006;63:197-202.

252. Castillo PR, Mignot E, Woodruff BK, Boeve BF. Undetectable CSF hypocretin-1 in "Hashimoto's encephalopathy" associated with coma. Neurology 2004;62:1909.

253. Sawka AM, Fatourechi V, Boeve BF, Mokri B. Rarity of encephalopathy associated with autoimmune thyroiditis: a case series from Mayo Clinic from 1950 to 1996. Thyroid 2002;12:393-398.

254. Schiess N, Pardo CA. Hashimoto's encephalopathy. Ann N Y Acad Sci 2008;1142:254-265.

255. Oide T, Tokuda T, Yazaki M, et al. Anti-neuronal autoantibody in Hashimoto's encephalopathy: neuropathological, immunohistochemical, and biochemical analysis of two patients. J Neurol Sci 2004;217:7-12.

256. Chen N, Qin W, Wei C, Wang X, Li K. Time course of Hashimoto's encephalopathy revealed by MRI: report of two cases. J Neurol Sci 2011;300:169-172.

257. Santoro D, Colombo I, Ghione I, et al. Steroid-responsive Hashimoto encephalopathy mimicking Creutzfeldt-Jakob disease. Neurol Sci 2011;32:719-722.

258. Doherty CP, Schlossmacher M, Torres N, et al. Hashimoto's encephalopathy mimicking Creutzfeldt-Jakob disease: brain biopsy findings. J Neurol Neurosurg Psychiatry 2002;73:601-602.

259. de Cerqueira AC, Bezerra JM, de Magalhaes GC, Rozenthal M, Nardi AE. Hashimoto's encephalopathy with clinical features similar to those of Creutzfeldt-Jakob disease. Arq Neuropsiquiatr 2008;66:903-905.

260. Spiegel J, Hellwig D, Becker G, Muller M. Progressive dementia caused by Hashimoto's encephalopathy - report of two cases. Eur J Neurol 2004;11:711-713.

261. Lopez-Giovaneli J, Moreaud O, Faure P, et al. Cortico-responsive encephalopathy associated with autoimmune thyroiditis (SREAT): about two case reports characterized by a gap between the diagnosis of autoimmune thyroiditis and neurological disorders. Ann Endocrinol (Paris) 2007;68:173-176.

262. Boers PM, Colebatch JG. Hashimoto's encephalopathy responding to plasmapheresis. J Neurol Neurosurg Psychiatry 2001;70:132.

263. Nieuwenhuis L, Santens P, Vanwalleghem P, Boon P. Subacute Hashimoto's encephalopathy, treated with plasmapheresis. Acta Neurol Belg 2004;104:80-83.

264. Nagpal T, Pande S. Hashimoto's encephalopathy: response to plasma exchange. Neurol India 2004;52:245-247.

265. Jacob S, Rajabally YA. Hashimoto's encephalopathy: steroid resistance and response to intravenous immunoglobulins. J Neurol Neurosurg Psychiatry 2005;76:455-456.
266. Tamura N, Matsudaira R, Hirashima M, et al. Two cases of refractory Wegener's granulomatosis successfully treated with rituximab. Intern Med 2007;46:409-414.

267. Hunter GR, Donat J, Pryse-Phillips W, Harder S, Robinson CA. Rasmussen's encephalitis in a 58-year-old female: still a variant? Can J Neurol Sci 2006;33:302-305.

268. Kupila L, Jutila L, Immonen A, et al. Late-onset Rasmussen's encephalitis and long-term remission. Epileptic Disord 2011;13:88 91.

269. Kashihara K, Ohno M, Takahashi Y. Twenty-one-year course of adult-onset Rasmussen's encephalitis and bilateral uveitis: case report. J Neurol Sci 2010;294:127-130.

270. Villani F, Pincherle A, Antozzi C, et al. Adult-onset Rasmussen's encephalitis: anatomical-electrographic-clinical features of 7 Italian cases. Epilepsia 2006;47(suppl 5):41-46.

271. McLachlan RS, Girvin JP, Blume WT, Reichman H. Rasmussen's chronic encephalitis in adults. Arch Neurol 1993;50:269-274.

272. Rogers SW, Andrews PI, Gahring LC, et al. Autoantibodies to glutamate receptor GluR3 in Rasmussen's encephalitis. Science 1994;265:648-651.

273. Bien CG, Bauer J, Deckwerth TL, et al. Destruction of neurons by cytotoxic T cells: a new pathogenic mechanism in Rasmussen's encephalitis. Ann Neurol 2002;51:311-318.

274. Mantegazza R, Bernasconi P, Baggi F, et al. Antibodies against GluR3 peptides are not specific for Rasmussen's encephalitis but are also present in epilepsy patients with severe, early onset disease and intractable seizures. J Neuroimmunol 2002;131:179 185.

275. Andrews PI, Dichter MA, Berkovic SF, Newton MR, McNamara JO. Plasmapheresis in Rasmussen's encephalitis. 1996. Neurology 2001;57:S37-S41.

276. Feasby T, Banwell B, Benstead T, et al. Guidelines on the use of intravenous immune globulin for neurologic conditions. Transfus Med Rev 2007;21:S57-S107.

277. Muto A, Oguni H, Takahashi Y, et al. Nationwide survey (incidence, clinical course, prognosis) of Rasmussen's encephalitis. Brain Dev 2011;32:445-453.

278. Granata T, Fusco L, Gobbi G, et al. Experience with immunomodulatory treatments in Rasmussen's encephalitis. Neurology 2003;61:1807-1810.

279. Vincent A, McConville J, Farrugia ME, Newsom-Davis J. Seronegative myasthenia gravis. Semin Neurol 2004;24:125-133.

280. Carr AS, Cardwell CR, McCarron PO, McConville J. A systematic review of population based epidemiological studies in Myasthenia Gravis. BMC Neurol 2010;10:46.

281. Alshekhlee A, Miles JD, Katirji B, Preston DC, Kaminski HJ. Incidence and mortality rates of myasthenia gravis and myasthenic crisis in US hospitals. Neurology 2009;72:1548-1554.

282. Hoch W, McConville J, Helms S, et al. Auto-antibodies to the receptor tyrosine kinase MuSK in patients with myasthenia gravis without acetylcholine receptor antibodies. Nat Med 2001;7:365-368.

283. McConville J, Farrugia ME, Beeson D, et al. Detection and characterization of MuSK antibodies in seronegative myasthenia gravis. Ann Neurol 2004;55:580-584.

284. Guptill JT, Sanders DB, Evoli A. Anti-MuSK antibody myasthenia gravis: clinical findings and response to treatment in two large cohorts. Muscle Nerve 2011;44:36-40.

285. Oosterhuis HJ. The natural course of myasthenia gravis: a long term follow up study. J Neurol Neurosurg Psychiatry 1989;52:1121-1127.

286. Phillips LH. The epidemiology of myasthenia gravis. Semin Neurol 2004;24:17-20.

287. Gajdos P, Chevret S, Toyka K. Plasma exchange for myasthenia gravis. Cochrane Database Syst Rev 2002:CD002275.

288. Gajdos P, Chevret S, Toyka K. Intravenous immunoglobulin for myasthenia gravis. Cochrane Database Syst Rev 2008;23: CD002277. 
289. Mandawat A, Kaminski HJ, Cutter G, Katirji B, Alshekhlee A. Comparative analysis of therapeutic options used for myasthenia gravis. Ann Neurol 2010;68:797-805.

290. Wirtz PW, van Dijk JG, van Doorn PA, et al. The epidemiology of the Lambert-Eaton myasthenic syndrome in the Netherlands. Neurology 2004;63:397-398.

291. Nicolle MW, Stewart DJ, Remtulla H, Chen R, Bolton CF. Lambert-Eaton myasthenic syndrome presenting with severe respiratory failure. Muscle Nerve 1996;19:1328-1333.

292. Jiang JR, Shih JY, Wang HC, et al. Small-cell lung cancer presenting with Lambert-Eaton myasthenic syndrome and respiratory failure. J Formos Med Assoc 2002;101:871-874.

293. Tseng A, Claussen GC, Oh SJ. Respiratory failure in lamberteaton myasthenic syndrome precipitated by calcium-channel blockers: report of a case and literature review. J Clin Neuromuscul Dis 2002;4:60-63.

294. Beydoun SR. Delayed diagnosis of Lambert-Eaton myasthenic syndrome in a patient presenting with recurrent refractory respiratory failure. Muscle Nerve 1994;17:689-690.

295. Barr CW, Claussen G, Thomas D, et al. Primary respiratory failure as the presenting symptom in Lambert-Eaton myasthenic syndrome. Muscle Nerve 1993;16:712-715.

296. Laroche CM, Mier AK, Spiro SG, et al. Respiratory muscle weakness in the Lambert-Eaton myasthenic syndrome. Thorax 1989;44:913-918.

297. Gracey DR, Southorn PA. Respiratory failure in Lambert-Eaton myasthenic syndrome. Chest 1987;91:716-718.

298. Collins LC. Respiratory failure secondary to Eaton-Lambert syndrome. J Ky Med Assoc 1986;84:665-666.

299. Keogh M, Sedehizadeh S, Maddison P. Treatment for LambertEaton myasthenic syndrome. Cochrane Database Syst Rev 2011;16: CD003279.

300. Dalakas MC, Fujii M, Li M, McElroy B. The clinical spectrum of anti-GAD antibody-positive patients with stiff-person syndrome. Neurology 2000;55:1531-1535.

301. Jarius S, Stich O, Speck J, et al. Qualitative and quantitative evidence of anti-glutamic acid decarboxylase-specific intrathecal antibody synthesis in patients with stiff-person syndrome. J Neuroimmunol 2010;229:219-224.

302. Rizzi M, Knoth R, Hampe CS, et al. Long-lived plasma cells and memory B cells produce pathogenic anti-GAD65 autoantibodies in Stiff-Person Syndrome. PLoS One 2010;5:e10838.

303. Holmoy T, Geis C. The immunological basis for treatment of stiff-person syndrome. J Neuroimmunol 2011;231:55-60.

304. Geis C, Weishaupt A, Hallermann S, et al. Stiff-person syndromeassociated autoantibodies to amphiphysin mediate reduced GABAergic inhibition. Brain 2010;133:3166-3180.

305. Geis C, Beck M, Jablonka S, et al. Stiff-person syndrome associated anti-amphiphysin antibodies reduce GABA associated [Ca $(2+)$ ] rise in embryonic motoneurons. Neurobiol Dis 2009;36:191199.

306. Butler MH, Hayashi A, Ohkoshi N, et al. Autoimmunity to gephyrin in Stiff-Man syndrome. Neuron 2000;26:307-312.

307. Mas N, Saiz A, Leite MI, et al. Antiglycine-receptor encephalomyelitis with rigidity. J Neurol Neurosurg Psychiatry 2010;82:1399-1401.

308. Turner MR, Irani SR, Leite MI, et al. Progressive encephalomyelitis with rigidity and myoclonus: Glycine and NMDA receptor antibodies. Neurology 2011;77:439-443.

309. Qureshi A, Hennessy M. Stiff-person syndrome (SPS) complicated by respiratory failure: successful treatment with rituximab. J Neurol 2011. doi:10.1007/s00415-011-6123-9.

310. Dalakas MC, Fujii M, Li M, et al. High-dose intravenous immune globulin for stiff-person syndrome. N Engl J Med 2001;345:1870-1876.

311. Donofrio PD, Berger A, Brannagan TH, 3rd, et al. Consensus statement: the use of intravenous immunoglobulin in the treatment of neuromuscular conditions report of the AANEM ad hoc committee. Muscle Nerve 2009;40:890-900.

312. Baker MR, Das M, Isaacs J, Fawcett PR, Bates D. Treatment of stiff-person syndrome with rituximab. J Neurol Neurosurg Psychiatry 2005;76:999-1001.

313. Hazin R, Abuzetun JY, Giglio P, Khan F. Agrypnia excitata: current concepts and future prospects in management. J Neuropsychiatry Clin Neurosci 2009;21:126-131.

314. Lugaresi E, Provini F. Agrypnia excitata: clinical features and pathophysiological implications. Sleep Med Rev 2001;5:313-322.

315. Lai C, Tian G, Takahashi T, et al. Neuromyelitis optica antibodies in patients with severe optic neuritis in China. J Neuroophthalmol 2011;31:16-19.

316. Vincent A, Irani SR. Caspr2 antibodies in patients with thymomas. J Thorac Oncol 2011;5:S277-S280.

317. Merchut MP. Management of voltage-gated potassium channel antibody disorders. Neurol Clin 2010;28:941-959.

318. Skeie GO, Apostolski S, Evoli A, et al. Guidelines for treatment of autoimmune neuromuscular transmission disorders. Eur J Neurol 2010;17:893-902.

319. Schroder A, Linker RA, Gold R. Plasmapheresis for neurological disorders. Expert Rev Neurother 2009;9:1331-1339.

320. Gross RA, Johnston KC. Levels of evidence: Taking Neurology to the next level. Neurology 2009;72:8-10.

321. Yuki N, Tagawa Y, Hirata K. Minimal number of plasma exchanges needed to reduce immunoglobulin in Guillain-Barre syndrome. Neurology 1998;51:875-877.

322. Kaplan AA, Halley SE. Plasma exchange with a rotating filter. Kidney Int 1990;38:160-166.

323. Dau PC. Increased proliferation of blood mononuclear cells after plasmapheresis treatment of patients with demyelinating disease. J Neuroimmunol 1990;30:15-21.

324. Glassman AB, Bennett CE. Alterations of lymphocyte responsiveness in Guillain-Barre syndrome. Effects of plasma exchange. Transfusion 1983;23:369-372.

325. Yoshii F, Shinohara Y. Impaired interleukin-2 response of mononuclear cells in Guillain-Barre syndrome. Eur J Neurol 2000; 7:303307.

326. Goto $\mathrm{H}$, Matsuo $\mathrm{H}$, Nakane $\mathrm{S}$, et al. Plasmapheresis affects $\mathrm{T}$ helper type-1/T helper type-2 balance of circulating peripheral lymphocytes. Ther Apher 2001;5:494-496.

327. Chien PJ, Yeh JH, Chiu HC, et al. Inhibition of peripheral blood natural killer cell cytotoxicity in patients with myasthenia gravis treated with plasmapheresis. Eur J Neurol 2011;18:1350-1357.

328. Randomised trial of plasma exchange, intravenous immunoglobulin, and combined treatments in Guillain-Barre syndrome. Plasma Exchange/Sandoglobulin Guillain-Barre Syndrome Trial Group. Lancet 1997;349:225-230.

329. Lehmann HC, Hartung HP. Plasma exchange and intravenous immunoglobulins: mechanism of action in immune-mediated neuropathies. J Neuroimmunol 2011;231:61-69.

330. Yeh JH, Chen WH, Chiu HC. Complications of double-filtration plasmapheresis. Transfusion 2004;44:1621-1625.

331. Couriel D, Weinstein R. Complications of therapeutic plasma exchange: a recent assessment. J Clin Apher 1994;9:1-5.

332. Lowenberg M, Stahn C, Hommes DW, Buttgereit F. Novel insights into mechanisms of glucocorticoid action and the development of new glucocorticoid receptor ligands. Steroids 2008;73:1025-1029.

333. Rhen T, Cidlowski JA. Antiinflammatory action of glucocorticoids - new mechanisms for old drugs. N Engl J Med 2005;353:1711-1723.

334. Gonzalo JA, Gonzalez-Garcia A, Martinez C, Kroemer G. Glucocorticoid-mediated control of the activation and clonal deletion of peripheral T cells in vivo. J Exp Med 1993;177:12391246. 
335. Hetherington SV, Quie PG. Human polymorphonuclear leukocytes of the bone marrow, circulation, and marginated pool: function and granule protein content. Am J Hematol 1985;20:235246.

336. Mager DE, Lin SX, Blum RA, Lates CD, Jusko WJ. Dose equivalency evaluation of major corticosteroids: pharmacokinetics and cell trafficking and cortisol dynamics. J Clin Pharmacol 2003;43:1216-1227.

337. Myhr KM, Mellgren SI. Corticosteroids in the treatment of multiple sclerosis. Acta Neurol Scand Suppl 2009:73-80.

338. Manson SC, Brown RE, Cerulli A, Vidaurre CF. The cumulative burden of oral corticosteroid side effects and the economic implications of steroid use. Respir Med 2009;103:975-994.

339. Weinstein RS. Clinical practice. Glucocorticoid-induced bone disease. N Engl J Med 2011;365:62-70.

340. Schacke H, Docke WD, Asadullah K. Mechanisms involved in the side effects of glucocorticoids. Pharmacol Ther 2002;96:2343.

341. Gauthier SA, Weiner HL. Cyclophosphamide therapy for MS. Int MS J 2005;12:52-58.

342. Perini P, Calabrese M, Rinaldi L, Gallo P. The safety profile of cyclophosphamide in multiple sclerosis therapy. Expert Opin Drug Saf 2007;6:183-190.

343. de Groot K, Harper L, Jayne DR, et al. Pulse versus daily oral cyclophosphamide for induction of remission in antineutrophil cytoplasmic antibody-associated vasculitis: a randomized trial. Ann Intern Med 2009;150:670-680.

344. Adu D, Pall A, Luqmani RA, et al. Controlled trial of pulse versus continuous prednisolone and cyclophosphamide in the treatment of systemic vasculitis. QJM 1997;90:401-109.

345. Guillevin L, Cordier JF, Lhote F, et al. A prospective, multicenter, randomized trial comparing steroids and pulse cyclophosphamide versus steroids and oral cyclophosphamide in the treatment of generalized Wegener's granulomatosis. Arthritis Rheum 1997;40:21872198.

346. Drachman DB, Brodsky RA. High-dose therapy for autoimmune neurologic diseases. Curr Opin Oncol 2005;17:83-88.

347. Gladstone DE, Brannagan TH, 3rd, Schwartzman RJ, Prestrud AA, Brodsky I. High dose cyclophosphamide for severe refractory myasthenia gravis. J Neurol Neurosurg Psychiatry 2004;75:789791.

348. Mok CC, To CH, Mak A, Poon WL. Immunoablative cyclophosphamide for refractory lupus-related neuromyelitis optica. J Rheumatol 2008;35:172-174.

349. Schwartzman RJ, Simpkins N, Alexander GM, et al. High-dose cyclophosphamide in the treatment of multiple sclerosis. CNS Neurosci Ther 2009;15:118-127.

350. Le Guenno G, Mahr A, Pagnoux C, Dhote R, Guillevin L. Incidence and predictors of urotoxic adverse events in cyclophosphamidetreated patients with systemic necrotizing vasculitides. Arthritis Rheum 2011;63:1435-1445.

351. Emadi A, Jones RJ, Brodsky RA. Cyclophosphamide and cancer: golden anniversary. Nat Rev Clin Oncol 2009;6:638-647.

352. Hartung HP. Advances in the understanding of the mechanism of action of IVIg. J Neurol 2008;255(suppl 3):3-6.

353. Gold R, Stangel M, Dalakas MC. Drug Insight: the use of intravenous immunoglobulin in neurology-therapeutic considerations and practical issues. Nat Clin Pract Neurol 2007;3:36-44.

354. Nimmerjahn F, Ravetch JV. Anti-inflammatory actions of intravenous immunoglobulin. Annu Rev Immunol 2008;26:513-33.

355. Jacobs BC, O'Hanlon GM, Bullens RW, et al. Immunoglobulins inhibit pathophysiological effects of anti-GQ1b-positive sera at motor nerve terminals through inhibition of antibody binding. Brain 2003;126:2220-2234.

356. Zhang G, Lopez PH, Li CY, et al. Anti-ganglioside antibodymediated neuronal cytotoxicity and its protection by intravenous immunoglobulin: implications for immune neuropathies. Brain 2004;127:1085-1100.

357. Piepers S, Jansen MD, Cats EA, et al. IVIg inhibits classical pathway activity and anti-GM1 IgM-mediated complement deposition in MMN. J Neuroimmunol 2010;229:256-262.

358. Yuki N, Watanabe H, Nakajima T, Spath PJ. IVIG blocks complement deposition mediated by anti-GM1 antibodies in multifocal motor neuropathy. J Neurol Neurosurg Psychiatry 2011;82:87-91.

359. Le Pottier L, Sapir T, Bendaoud B, et al. Intravenous immunoglobulin and cytokines: focus on tumor necrosis factor family members BAFF and APRIL. Ann N Y Acad Sci 2007;1110:426432.

360. Bayry J, Lacroix-Desmazes S, Kazatchkine MD, Kaveri SV. Monoclonal antibody and intravenous immunoglobulin therapy for rheumatic diseases: rationale and mechanisms of action. Nat Clin Pract Rheumatol 2007;3:262-272.

361. Nimmerjahn F, Ravetch JV. Fcgamma receptors as regulators of immune responses. Nat Rev Immunol 2008;8:34-47.

362. Tackenberg B, Jelcic I, Baerenwaldt A, et al. Impaired inhibitory Fcgamma receptor IIB expression on B cells in chronic inflammatory demyelinating polyneuropathy. Proc Natl Acad Sci U S A 2009;106:4788-4792.

363. Creange A, Gregson NA, Hughes RA. Intravenous immunoglobulin modulates lymphocyte CD54 and monocyte FcgammaRII expression in patients with chronic inflammatory neuropathies. J Neuroimmunol 2003;135:91-95.

364. Sharief MK, Ingram DA, Swash M, Thompson EJ. I.v. immunoglobulin reduces circulating proinflammatory cytokines in Guillain-Barre syndrome. Neurology 1999;52:1833-1838.

365. Exley AR, Smith N, Winer JB. Tumour necrosis factor-alpha and other cytokines in Guillain-Barre syndrome. J Neurol Neurosurg Psychiatry 1994;57:1118-1120.

366. Chen C, Danekas LH, Ratko TA, Vlasses PH, Matuszewski KA. A multicenter drug use surveillance of intravenous immunoglobulin utilization in US academic health centers. Ann Pharmacother 2000;34:295-299.

367. Fergusson D, Hutton B, Sharma M, et al. Use of intravenous immunoglobulin for treatment of neurologic conditions: a systematic review. Transfusion 2005;45:1640-1657.

368. Hughes RA, Raphael JC, Swan AV, van Doorn PA. Intravenous immunoglobulin for Guillain-Barre syndrome. Cochrane Database Syst Rev 2006:CD002063.

369. Zinman L, Ng E, Bril V. IV immunoglobulin in patients with myasthenia gravis: a randomized controlled trial. Neurology 2007;68:837-841.

370. Sorensen PS, Haas J, Sellebjerg F, Olsson T, Ravnborg M. IV immunoglobulins as add-on treatment to methylprednisolone for acute relapses in MS. Neurology 2004;63:2028-2033.

371. Roed HG, Langkilde A, Sellebjerg F, et al. A double-blind, randomized trial of IV immunoglobulin treatment in acute optic neuritis. Neurology 2005;64:804-810.

372. Sahlas DJ, Miller SP, Guerin M, Veilleux M, Francis G. Treatment of acute disseminated encephalomyelitis with intravenous immunoglobulin. Neurology 2000;54:1370-1372.

373. Fu DC, Montgomery JR. High-dose, rapid-infusion IVIG in postvaccination acute disseminated encephalomyelitis. Neurology 2008;71:294-295.

374. Ravaglia S, Piccolo G, Ceroni M, et al. Severe steroid-resistant post-infectious encephalomyelitis: general features and effects of IVIg. J Neurol 2007;254:1518-1523.

375. Shahar E, Andraus J, Savitzki D, Pilar G, Zelnik N. Outcome of severe encephalomyelitis in children: effect of high-dose methylprednisolone and immunoglobulins. J Child Neurol 2002;17:810-814.

376. Paran D, Herishanu Y, Elkayam O, Shopin L, Ben-Ami R. Venous and arterial thrombosis following administration of intravenous immunoglobulins. Blood Coagul Fibrinolysis 2005;16:313-318. 
377. Ballow M. Safety of IGIV therapy and infusion-related adverse events. Immunol Res 2007;38:122-132.

378. Orbach H, Katz U, Sherer Y, Shoenfeld Y. Intravenous immunoglobulin: adverse effects and safe administration. Clin Rev Allergy Immunol 2005;29:173-184.

379. Duhem C, Dicato MA, Ries F. Side-effects of intravenous immune globulins. Clin Exp Immunol 1994;97(suppl 1):79-83.

380. Kosmidis ML, Dalakas MC. Practical considerations on the use of rituximab in autoimmune neurological disorders. Ther Adv Neurol Disord;3:93-105.

381. Bielekova B, Becker BL. Monoclonal antibodies in MS: mechanisms of action. Neurology;74(suppl 1):S31-S40.

382. Ferraro AJ, Drayson MT, Savage CO, MacLennan IC. Levels of autoantibodies, unlike antibodies to all extrinsic antigen groups, fall following B cell depletion with Rituximab. Eur J Immunol 2008;38:292-298.

383. Reis EA, Athanazio DA, Lima I, et al. NK and NKT cell dynamics after rituximab therapy for systemic lupus erythematosus and rheumatoid arthritis. Rheumatol Int 2009;29:469-475.

384. Bielekova B, Catalfamo M, Reichert-Scrivner S, et al. Regulatory CD56(bright) natural killer cells mediate immunomodulatory effects of IL-2Ralpha-targeted therapy (daclizumab) in multiple sclerosis. Proc Natl Acad Sci U S A 2006;103:59415946.

385. Hauser SL, Waubant E, Arnold DL, et al. B-cell depletion with rituximab in relapsing-remitting multiple sclerosis. N Engl J Med 2008;358:676-688.

386. Hawker K, O'Connor P, Freedman MS, et al. Rituximab in patients with primary progressive multiple sclerosis: results of a randomized double-blind placebo-controlled multicenter trial. Ann Neurol 2009;66:460-471.

387. Wang T, Weigt SS, Belperio JA, Lynch JP. Immunosuppressive and cytotoxic therapy: pharmacology, toxicities, and monitoring. Semin Respir Crit Care Med;32:346-370.

388. Carson KR, Evens AM, Richey EA, et al. Progressive multifocal leukoencephalopathy after rituximab therapy in HIVnegative patients: a report of 57 cases from the Research on Adverse Drug Events and Reports project. Blood 2009;113:4834 4840.

389. Clifford DB, Ances B, Costello C, et al. Rituximab-associated progressive multifocal leukoencephalopathy in rheumatoid arthritis. Arch Neurol 2011;68:1156-1164. 